Synthesis, Self-Assembly, and Solar Cell Performance of N-Annulated Perylene Diimide Non-Fullerene Acceptors

\title{
SUPPLIMENTARY INFORMATION
}

Arthur D Hendsbee ${ }^{a^{\dagger}}$, Jon-Paul Sun ${ }^{b^{\dagger}}$, Wai Kit Law ${ }^{c}$, He Yan ${ }^{c, d}$, Ian G Hill ${ }^{b}$, Denis M Spasyuk ${ }^{e}$, Gregory C Welch $^{\mathrm{a}^{*}}$

${ }^{a}$ Department of Chemistry, University of Calgary, 2500 University Drive N.W., Calgary, Alberta, Canada T2N $1 \mathrm{~N} 4$

${ }^{\mathrm{b}}$ Department of Physics, Dalhousie University, 6274 Coburg Road, Halifax, Nova Scotia, Canada B3H 4R2

${ }^{\mathrm{c}}$ Department of Chemistry and Energy Institute, The Hong Kong University of Science and Technology, Clear Water Bay, Hong Kong

${ }^{d}$ The Hong Kong University of Science and Technology-Shenzhen Research Institute No. 9, Yuexing 1st Road, Hi-tech Park, Nanshan Shenzhen 518057, China

${ }^{\text {e}}$ Canadian Light Source Inc. 44 Innovation Blvd, Saskatoon, Saskatchewan Canada SK S7N 2V3

${ }^{+}$Authors contributed equally

* Corresponding Author

Email: gregory.welch@ucalgary.ca

Phone Number: 1-403-210-7603

Materials and Methods S2-S4

Synthetic Details S4-S9

Solution ${ }^{1} \mathrm{H}$ and ${ }^{13} \mathrm{C}$ NMR spectra S10-S18

Solubility Curves S19-S20

Mass Spectrometry S21-S23

DFT calculations S24

Device Fabrication and AFM Data S25-S34

Optical and Electronic Characterization S34

Crystal Structure Data S35-S36

TGA Analysis S36

References S37 


\section{Materials and methods}

General synthetic details: Reactions were carried out on a bench top or under an atmosphere of dry, $\mathrm{O}_{2}$ free $\mathrm{N}_{2}$ where indicated. For reactions requiring heat, the conventional method involved submerging reaction vial in a LabArmor $^{\circledR}$ bead bath and heating on a hot plate at the desired temperature. For reactions that made use of microwave-assisted synthesis a Biotage ${ }^{\circledR}$ Initiator+ microwave reactor was used. The operational power range of this instrument is $0-400 \mathrm{~W}$ using a $2.45 \mathrm{GHz}$ magnetron.

Materials: All materials and solvents were purchased from Sigma-Aldrich unless indicated otherwise. Homogeneous catalyst $\mathrm{Pd}(\mathrm{DBA})_{2}$ was purchased from STREM chemicals and use without further purification. PTB7 and PTB7-Th were purchased from 1-material. P3TEA was made as described in ref. 73.

Nuclear Magnetic Resonance (NMR): Reported ${ }^{1} \mathrm{H}$ and ${ }^{13} \mathrm{C}$ NMR spectra were acquired on either Bruker Ascend $500 \mathrm{mHz}$, Avance $400 \mathrm{mHZ}$ or DRX $400 \mathrm{mHz}$ spectrometers all at $300 \mathrm{~K}$. Chemical shifts are reported in parts per million (ppm) and are referenced to the external standard $\mathrm{SiMe}_{4}$. All experiments were performed in deuterated chloroform $\left(\mathrm{CDCl}_{3}\right)$. Multiplicities are reported as: singlet (s), doublet (d), triplet $(\mathrm{t})$, quartet $(q)$, doublet of doublets (dd), and multiplet $(\mathrm{m})$.

Mass Spectrometry (MS): Mass spectrometry measurements were performed courtesy of Wade White in the Chemical Instrumentation Facility at the University of Calgary. All samples were run on an Agilent 6520 Q-TOF through direct infusion experiments with an Agilent 1200 series HPLC without a column. The flow rate was $0.2 \mathrm{~mL} /$ minute using methanol as the eluting solvent. The source conditions were a gas temperature of $300^{\circ} \mathrm{C}$ with a flow of $10 \mathrm{~L} / \mathrm{min}$, a vaporizer temperature of $350^{\circ} \mathrm{C}$ and a nebulizer pressure of 12 psi.

Cyclic Voltammetry (CV): All electrochemical measurements were performed using a $\mathrm{CH}$ Instruments potentiostat in a standard three-electrode configuration equipped with a silver wire pseudo-reference, platinum wire counter electrode and glassy carbon working electrode. The cyclic voltammetry experiments were performed in an anhydrous solution of dichloromethane $\left(\mathrm{CH}_{2} \mathrm{Cl}_{2}\right)$ with $0.1 \mathrm{M}$ tetrabutylammoniumhexafluorophosphate $\left(\mathrm{TBAPF}_{6}\right)$ supporting electrolyte. Samples were scanned at a rate of $100 \mathrm{mV} / \mathrm{s}$ following a dry $\mathrm{N}_{2}$ purge to deoxygenate the solution. Solution $\mathrm{CV}$ measurements were carried out with a sample concentration of $\sim 0.5 \mathrm{mg} / \mathrm{mL}$ in $\mathrm{CH}_{2} \mathrm{Cl}_{2}$. Estimations of the energy levels were obtained by correlating the onset $\left(\mathrm{E}_{\mathrm{ox}} \mathrm{Fc} / \mathrm{Fc}+, \mathrm{E}_{\mathrm{red}} \mathrm{Fc} / \mathrm{Fc}+\right)$ to the normal hydrogen electrode (NHE), assuming a IP energy of $4.80 \mathrm{eV}$ for $\mathrm{Fc} / \mathrm{Fc}+$ :

$E(I P)=\left(E_{o x}+4.80\right), E(E A)=\left(E_{r e d}+4.80\right)$

UV-Visible Spectroscopy (UV/vis): All absorption measurements were recorded using an Agilent Technologies Cary 60 UV-vis spectrometer at room temperature. All solution UV/vis experiments were run in chloroform $\left(\mathrm{CHCl}_{3}\right)$ using $2 \mathrm{~mm}$ quartz cuvettes and diluted $1 \% \mathrm{wt} / \mathrm{v}$ solutions. Thin-films were prepared by spin-coating $1 \% \mathrm{wt} / \mathrm{v}$ solutions from $\mathrm{CHCl}_{3}$ onto Corning glass micros slides at $5000 \mathrm{rpm}$. Prior to use, glass slides were cleaned with soap and water, acetone and isopropanol, and followed by UV/ozone treatment using a Novascan UV/ozone cleaning system. 
Density Functional Theory: Calculations were done on Gaussian09, ${ }^{1}$ input files and results were visualized using GausView05. ${ }^{2}$ All alkyl chains were replaced with a methyl group. The B3LYP ${ }^{3-5}$ level of theory with 6-31G $(d)^{6-11}$ basis set were used for the calculations. TD-DFT ${ }^{12}$ calculations were performed from the optimized geometries. Single point calculations were performed on optimized structures in order to generate molecular orbitals and electrostatic potential maps.

Melting Point Determination: The melting or decomposition points were determined using a Stuart SMP40 apparatus operating from 50 to $400{ }^{\circ} \mathrm{C}$ with a ramp rate of $20^{\circ} \mathrm{C}$ per minute.

\section{Crystal Structure Determination.}

Single crystal X-ray diffraction (SC-XRD) data for compounds $\mathbf{5}$ and $\mathbf{7}$ was collected using the Canadian Macromolecular Crystallography Facility beamlines CMCF-ID and CMCF-BM at the Canadian Light Source (CLS). ${ }^{13}$ CMCF-ID is an undulator beamline equipped with a $\mathrm{Si}$ (111) double crystal monochromator, Rayonix MX300 CCD detector with an active area of $300 \mathrm{~mm}$ x $300 \mathrm{~mm}$ and single-axis Huber 410 goniometer equipped with an $x / y$ stage. CMCF-BM is a bending magnet beamline equipped with a Si (111) double crystal monochromator, Rayonix MX300HE CCD detector and MD2 microdiffractometer equipped with Mini Kappa Goniometer Head.

Data for compound 5 was collected at $18.000 \mathrm{KeV}(0.68881 \AA$, CMCF-BM) using a single crystal and data for compound 7 was collected at $12.658 \mathrm{KeV}$ (0.97949 $\AA$, CMCF-ID) using multiple crystals. All data was collected at low temperature (100 K).

Cell refinement and data reduction were performed using XDS. ${ }^{14}$ An empirical absorption correction, based on the multiple measurements of equivalent reflections, and merging of data was performed using SADABS. ${ }^{15}$ Data conversion from XDS file format to SADABS file format was performed using XDS2SAD. ${ }^{16}$ The space group was confirmed by XPREP routine. ${ }^{17}$

The structure for compound $\mathbf{5}$ was solved by direct-methods and refined by full-matrix least squares and difference Fourier techniques with SHELXL-2014. ${ }^{18}$

The initial model and difference Fourier map for the compound 7 was obtained with SHELXL-2014 using merged data from three crystals. The crystal structure of $\mathbf{7}$ was solved by combination of direct-methods and real space refinement. Real-space refinement was performed using COOT. ${ }^{19}$ Direct-methods refinement was performed with SHELXL-2014 ${ }^{18}$ using conjugate-gradient refinement (CGLS) in the initial stages and then by full-matrix least-squares and difference Fourier techniques at the final stages. All the crystals collected for this compound were polysynthetic twins with two major crystalline domains. Twin law was calculated using TwinRotMat. ${ }^{20}$ Due to the nature of the crystalline material good quality data could not be obtained for this compound. The crystals only diffracted to $1.3 \AA$ and were polysynthetic in nature. Due to the crystals size $(1 \times 4 \times 10$ microns) and rapid crystal degradation in the $\mathrm{X}$-ray beam the data for this compound was collected using multiple crystals and then combined to achieve reasonable data completeness. However, only data from 3 crystals was successfully merged. Any additional data incorporation lead to significant deterioration of overall data quality ( $R_{\text {int }}$ and $R_{\text {sigma }}>20 \%$ ). 
All publication materials (CIF files validation, listings of bonds and angles, and ORTEP drawings) were prepared using LinXTL ${ }^{21}$, Mercury ${ }^{22}$, and PyMOL ${ }^{23}$ programs. Routine checkCIF and structure factor analyses were performed by Platon. ${ }^{20}$

\section{Synthetic Details:}

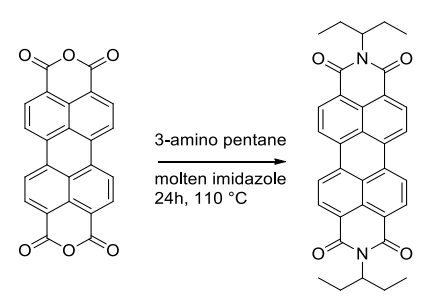

Synthesis of EP-PDI (2): The synthesis of EP-PDI was carried out using previously reported reaction conditions from the literature. ${ }^{24}$ Yield: $1.28 \mathrm{~g}(94 \%)$. Spectroscopic data for this compound matched those previously reported..$^{24}$

Scaled up Synthesis of EP-PDI (2): The synthesis of EP-PDI was carried out using previously reported reaction conditions from the literature. ${ }^{24}$ Yield: $13.4 \mathrm{~g}$ (98\%). Spectroscopic data for this compound matched those previously reported. ${ }^{24}$

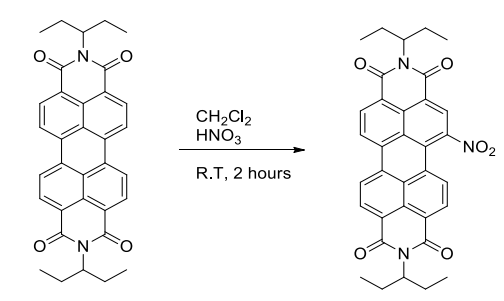

Synthesis of EP-NO2-PDI (3): The synthesis of EP-NO2-PDI was carried out using previously reported reaction conditions from the literature. ${ }^{25} \mathrm{EP}-\mathrm{PDI}\left((2), 2.6 \mathrm{~g}, 4.9 * 10^{-3} \mathrm{~mol}\right)$ was added to a $250 \mathrm{~mL}$ round bottom flask containing a stir-bar. Anhydrous dichloromethane $\sim 150 \mathrm{~mL}$ was then added as the solvent. While stirring, concentrated nitric acid $(6.0 \mathrm{~g}, 4.0 \mathrm{~mL})$ was added drop-wise in air. After the complete addition of $\mathrm{HNO}_{3}$, the reaction mixture was allowed to stir under air for 2 hours while being monitored by TLC. After two hours TLC analysis indicated the complete conversion to the desired product. The reaction mixture was then poured into water and the organic product extracted with dichloromethane. The aqueous waste phase was then neutralized with sodium hydroxide prior to disposal. The organic phase was collected and the solvent was removed in vacuo. The resulting red solid was slurried in methanol and filtered to obtain a bright red solid. Yield $2.7 \mathrm{~g}(96 \%) .{ }^{1} \mathrm{H}$ NMR (Chloroform-d, TMS/ppm) 8: 8.75-8.56 (m, $6 \mathrm{H}), 8.23-8.22(\mathrm{~m}, 1 \mathrm{H}), 5.03-5.00(\mathrm{~m}, 2 \mathrm{H}), 2.29-2.16(\mathrm{~m}, 4 \mathrm{H}), 1.99-1.86(\mathrm{~m}, 4 \mathrm{H}), 0.89\left(\mathrm{t}, 12 \mathrm{H},{ }^{3} \mathrm{~J}_{\mathrm{H}-\mathrm{H}}=7 \mathrm{~Hz}\right)$. ${ }^{13}$ C NMR (Chloroform-d, TMS/ppm) $\delta: 147.74,135.52,132.97,129.53,129.41,129.16,127.94,127.56$, $126.67,126.50,124.49,124.03,58.25,57.96,25.00,24.91,11.30,11.27$.

Scaled up Synthesis of EP-NO2-PDI (3): The synthesis of EP-NO2-PDI was carried out using previously reported reaction conditions from the literature. ${ }^{25} \mathrm{EP}-\mathrm{PDI}\left((2), 10 \mathrm{~g}, 1.9 * 10^{-2} \mathrm{~mol}\right)$ was added to a $1 \mathrm{~L}$ round bottom flask containing a stir-bar. Anhydrous dichloromethane $\sim 500 \mathrm{~mL}$ was then added as the solvent. While stirring, concentrated nitric acid $(20 \mathrm{~g}, 13.3 \mathrm{~mL})$ was added drop-wise in air. After the complete addition of $\mathrm{HNO}_{3}$, the reaction mixture was allowed to stir under air for 2 hours while being monitored by 
TLC. After 2 hours TLC analysis indicated the complete conversion to the desired product. The reaction mixture was then poured into water and the organic product extracted with dichloromethane. The aqueous waste phase was then neutralized with sodium hydroxide prior to disposal. The organic phase was collected and the solvent was removed in vacuo. The resulting red solid was slurried in methanol and filtered to obtain a bright red solid. Yield $10.7 \mathrm{~g}(98 \%)$.

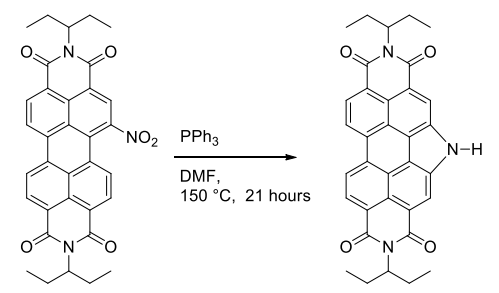

Synthesis of EP-NH-CAG-PDI (4): The synthesis of EP-NH-CAG-PDI was carried out using a modified literature procedure. ${ }^{26} \mathrm{EP}-\mathrm{NO2}-\mathrm{PDI}\left((3), 2.7 \mathrm{~g}, 4.7^{*} 10^{-3} \mathrm{~mol}\right)$ and triphenylphosphine $\left(4.0 \mathrm{~g}, 1.5^{*} 10^{-2} \mathrm{~mol}\right)$ were combined in a $100 \mathrm{~mL}$ Schlenk flask with a stir-bar. The flask was sealed with a septa and approximately $60 \mathrm{~mL}$ dry $\mathrm{N}, \mathrm{N}^{\prime}$-dimethylformamide was added using a syringe. The reaction mixture was purged with nitrogen for 5 minutes, followed by heating at $150{ }^{\circ} \mathrm{C}$ for 21 hours, at which time TLC indicated that starting material had been consumed. The reaction mixture was allowed to cool to room temperature and the solvent was removed using a rotary evaporator leaving a crude solid in the flask. The crude solid was loaded onto silica gel and purified using column chromatography (Hexane to Dichloromethane gradient, product eluted in $5 \%$ acetone in dichloromethane). The solvent was removed from the product fraction in vacuo resulting in a solid in the round-bottom flask which was taken up in a minimum of dichloromethane and precipitated into hexanes to give a red precipitate. The precipitated product was filtered using a Buchner funnel and rinsed with approximately $100 \mathrm{~mL}$ of hexanes to give a dark red solid. Yield: $1.6 \mathrm{~g}(61 \%) .{ }^{1} \mathrm{H}$ NMR (Chloroform-d, TMS/ppm) $\delta: 9.79(\mathrm{~s}, 1 \mathrm{H}), 9.04-8.86(\mathrm{~m}, 6 \mathrm{H})$, 5.22-5.17 (m, 2H), 2.38-2.30 (m, 4H), 2.03-1.96 (m, 4H), $0.96\left(\mathrm{t}, 12 \mathrm{H},{ }^{3} \mathrm{~J}_{\mathrm{H}-\mathrm{H}}=7 \mathrm{~Hz}\right)$. Due to the low solubility of compound (4) ${ }^{13} \mathrm{C}$ NMR was not obtained. Melting point: Compound remained solid up to $400{ }^{\circ} \mathrm{C}$ with no apparent decomposition.

Scaled up Synthesis of EP-NH-CAG-PDI (4): The synthesis of EP-NH-CAG-PDI was carried out using a modified literature procedure. ${ }^{26}$ EP-NO2-PDI ((3), $\left.10.73 \mathrm{~g}, 1.9 * 10^{-2} \mathrm{~mol}\right)$ and triphenylphosphine $(15.9 \mathrm{~g}$, $6.0^{*} 10^{-2} \mathrm{~mol}$ ) were combined in a $500 \mathrm{~mL}$ Schlenk flask with a stir-bar. The flask was sealed with a septa and approximately $240 \mathrm{~mL}$ dry N,N'-dimethylformamide was added using a cannula transfer method. The reaction mixture was purged with nitrogen for 10 minutes, followed by heating at $150{ }^{\circ} \mathrm{C}$ for 23 hours, at which time TLC indicated that starting material had been consumed. The reaction mixture was allowed to cool to room temperature and the solvent was removed in vacuo leaving a crude solid in the flask to which was added $\sim 100 \mathrm{~mL}$ dichloromethane. The product was slurried in dichloromethane for approximately 30 minutes, followed by the addition of $\sim 400 \mathrm{~mL}$ hexanes and further stirring for 30 minutes resulting in a red precipitate. The precipitated product was filtered using a Buchner funnel and rinsed with approximately $400 \mathrm{~mL}$ of 1:4 dichloromethane:hexanes to give a dark red solid. Yield: $6.8 \mathrm{~g}(67 \%)$. 


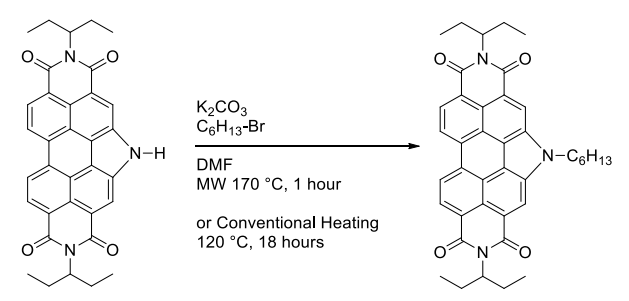

Synthesis of EP-N-Hex-CAG-PDI (5): The synthesis of EP-N-Hex-CAG-PDI was carried out using a modified literature procedure. ${ }^{27}$ EP-NH-CAG-PDI ((4), $\left.0.50 \mathrm{~g}, 9.2 * 10^{-4} \mathrm{~mol}\right)$ and potassium carbonate $(0.25 \mathrm{~g}$, $1.8^{*} 10^{-3} \mathrm{~mol}$ ) were combined in a $20 \mathrm{~mL}$ microwave vial with a stir-bar. The vial was sealed with a Teflon ${ }^{\circledR}$ cap and approximately $20 \mathrm{~mL}$ Dry N,N'-dimethylformamide was added using a syringe followed by the addition of 1-bromo-hexane $\left(0.27 \mathrm{~g}, 1.7^{*} 10^{-3} \mathrm{~mol}\right)$. The reaction mixture was purged with nitrogen for 5 minutes, followed by microwave heating at $170{ }^{\circ} \mathrm{C}$ for 1 hour. The reaction mixture was allowed to cool to room temperature and was extracted using water and dichloromethane. The organic phase was collected and the solvent was removed using a rotary evaporator to give a crude solid. The crude product was loaded onto silica gel and purified using column chromatography (hexane to dichloromethane gradient. The product eluted at approximately $80 \%$ dichloromethane). The product fraction was collected and the solvent was removed in vacuo to give a red solid. The red solid in the round-bottom flask was slurried in methanol and filtered to give a red solid. Yield: $0.40 \mathrm{~g}(70 \%) .{ }^{1} \mathbf{H}$ NMR (Chloroform-d, TMS/ppm) $\delta: ~ 8.98-8.96(m, 4 H), 8.85-8.83(\mathrm{~m}, 2 \mathrm{H}), 5.23-5.17(\mathrm{~m}, 2 \mathrm{H}), 4.85\left(\mathrm{t}, 2 \mathrm{H},{ }^{3} \mathrm{~J}_{\mathrm{H}-\mathrm{H}}=7 \mathrm{~Hz}\right), 2.38-2.31$ $(\mathrm{m}, 4 \mathrm{H}), 2.20-2.17(\mathrm{~m}, 2 \mathrm{H}), 2.03-1.97(\mathrm{~m}, 4 \mathrm{H}), 1.46-1.25(\mathrm{~m}, 6 \mathrm{H}), 0.96\left(\mathrm{t}, 12 \mathrm{H},{ }^{3} \mathrm{~J}_{\mathrm{H}-\mathrm{H}}=7 \mathrm{~Hz}\right), 0.85\left(\mathrm{t}, 3 \mathrm{H},{ }^{3} \mathrm{~J}_{\mathrm{H}-}\right.$ $\mathrm{H}=7 \mathrm{~Hz}$ ). ${ }^{13} \mathrm{C}$ NMR (Chloroform-d, TMS/ppm) $\delta: 134.18,132.05,124.06,123.24,121.19,118.89,57.21$, 46.38, 30.94, 30.77, 26.28, 24.68, 21.90, 13.38, 10.94 LRMS (APCI). m/z exp: 628.31 obtained: 628.48. Melting Point: $235^{\circ} \mathrm{C}$

Scaled up Synthesis of EP-N-Hex-CAG-PDI (5): The synthesis of EP-N-Hex-CAG-PDI was carried out using a modified literature procedure. ${ }^{27}$ EP-NH-CAG-PDI ((4), $6.81 \mathrm{~g}, 1.3^{*} 10^{-2} \mathrm{~mol}$ ) and potassium carbonate $\left(3.17 \mathrm{~g}, 2.3 * 10^{-2} \mathrm{~mol}\right)$ were combined in a $250 \mathrm{~mL}$ Schlenk flask with a stir-bar. The flask was sealed with a septa and approximately $200 \mathrm{~mL}$ dry $\mathrm{N}, \mathrm{N}^{\prime}$-dimethylformamide was added using a cannula transfer method. The reaction mixture was purged with nitrogen while reaching the reaction temperature of 120 ${ }^{\circ} \mathrm{C}$ at which time 1 -bromo-hexane $\left(3.08 \mathrm{~g}, 1.9 * 10^{-2} \mathrm{~mol}\right)$ was added using a syringe. The reaction mixture was allowed to stir at a temperature of $120^{\circ} \mathrm{C}$ for 18 hours under nitrogen at which time TLC analysis indicated complete consumption of the starting material. The reaction mixture was then allowed to cool to room temperature and was poured into water and the organic product extracted with dichloromethane. The organic phase was collected and the solvent was removed in vacuo to give a red solid. The red solid in the round-bottom flask was slurried in methanol and filtered to give a red solid. Yield: $7.0 \mathrm{~g}(89 \%)$.

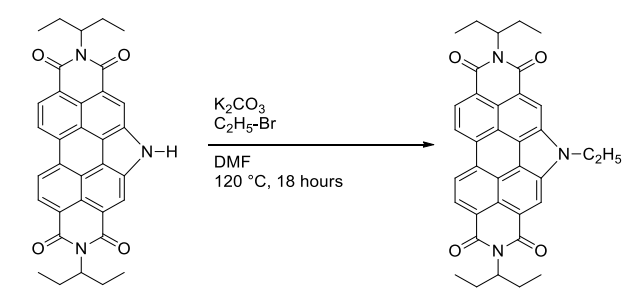

Synthesis of EP-N-Ethyl-CAG-PDI (5b): The synthesis of EP-N-Ethyl-CAG-PDI was carried out in an identical manner to the synthesis of 6 , by substituting hexyl bromide for an equimolar amount of ethyl bromide. Starting with $1 \mathrm{~g}$ of (4), $1.0 \mathrm{~g}$ of (5b) was obtained, (Yield: 96\%). ${ }^{1} \mathrm{H}$ NMR (Chloroform-d, TMS/ppm) $\delta$ : 
9.03-9.00 (m, 4H), 8.88-8.86 (m 2H), 5.26-5.20 (m 2H), $4.97\left(\mathrm{q}, 2 \mathrm{H},{ }^{3} \mathrm{~J}_{\mathrm{H}-\mathrm{H}}=7.5 \mathrm{~Hz}\right), 2.37-2.33(\mathrm{~m} 4 \mathrm{H}), 2.01-$ $1.98(\mathrm{~m}, 4 \mathrm{~h}), 1.82\left(\mathrm{t} 4 \mathrm{H}^{3} \mathrm{~J}_{\mathrm{H}-\mathrm{H}}=7.5 \mathrm{~Hz}\right), 0.97\left(\mathrm{t}, 12 \mathrm{H},{ }^{3} \mathrm{~J}_{\mathrm{H}-\mathrm{H}}=7.5 \mathrm{~Hz}\right)$

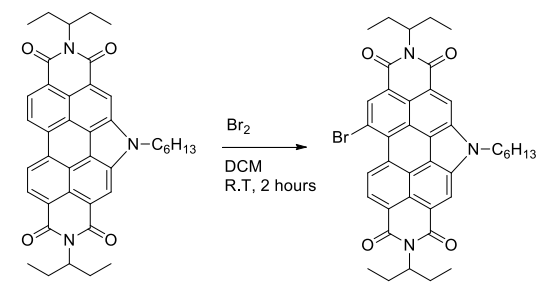

Synthesis of Br-EP-N-Hex-CAG-PDI (6): The synthesis of Br-EP-N-Hex-CAG-PDI was carried out using a modified literature procedure. ${ }^{28}$ EP-N-Hex-CAG-PDI ((5), $0.44 \mathrm{~g}, 9.2 * 10^{-4} \mathrm{~mol}$ ) was added to a $30 \mathrm{~mL}$ vial with a stir-bar. Approximately $25 \mathrm{~mL}$ of dichloromethane was added followed by a pipette full of $\mathrm{Br}_{2}$ (approximately 100 equivalents), and the vial was sealed with a Teflon ${ }^{\circledR}$ cap. The reaction mixture was allowed to stir at room temperature for 2 hours at which time TLC analysis indicated the complete consumption of starting material. The excess of bromine was removed using air bubbling and solvent was removed in vacuo to give a crude solid. The crude solid was loaded on silica gel and purified using column chromatography (hexane to dichloromethane gradient. The product compound eluted at approximately $80 \%$ dichloromethane). The solvent was removed from the product fraction using a rotary evaporator resulting in a solid in the round-bottom flask which was slurried in methanol and filtered to give a dark red solid. Yield: $0.47 \mathrm{~g}(94 \%) .{ }^{1} \mathrm{H}$ NMR (Chloroform-d, TMS/ppm) $\delta: 10.28\left(\mathrm{~d}, 1 \mathrm{H},{ }^{3} \mathrm{~J}_{\mathrm{H}-\mathrm{H}}=9 \mathrm{~Hz}\right), 9.07-9.04$ $(\mathrm{m}, 3 \mathrm{H}), 8.91-8.89(\mathrm{~m}, 1 \mathrm{H}), 5.22-5.16(\mathrm{~m}, 2 \mathrm{H}), 4.90\left(\mathrm{t}, 2 \mathrm{H},{ }^{3} \mathrm{~J}_{\mathrm{H}-\mathrm{H}}=7 \mathrm{~Hz}\right), 2.37-2.30(\mathrm{~m}, 4 \mathrm{H}), 2.20-2.16(\mathrm{~m}, 2 \mathrm{H})$, 2.02-1.98 (m, 4H), 1.46-1.27 (m, 6H), $1.04\left(\mathrm{t}, 6 \mathrm{H},{ }^{3} \mathrm{~J}_{\mathrm{H}-\mathrm{H}}=7 \mathrm{~Hz}\right), 1.02\left(\mathrm{t}, 6 \mathrm{H},{ }^{3} \mathrm{~J}_{\mathrm{H}-\mathrm{H}}=7 \mathrm{~Hz}\right), 0.85\left(\mathrm{t}, 3 \mathrm{H},{ }^{3} \mathrm{~J}_{\mathrm{H}-\mathrm{H}}=7\right.$ $\mathrm{Hz}$ ). ${ }^{13} \mathrm{C}$ NMR (Chloroform-d, TMS/ppm) $\delta: 134.36,134.16,132.12,130.19,127.33,124.05,123.46$, 123.08, 121.95, 121.25, 118.58, 118.15, 58.07, 57.91, 46.82, 31.29, 26.82, 25.23, 25.17, 22.42, 13.88, 11.50. LRMS (APCI). $\mathrm{m} / \mathrm{z}$ exp: 707.22, obtained: 707.44 .

Scaled up Synthesis of Br-EP-N-Hex-CAG-PDI (6): The synthesis of Br-EP-N-Hex-CAG-PDI was carried out using a modified literature procedure. ${ }^{28}$ EP-N-Hex-CAG-PDI ((5), $6.5 \mathrm{~g}, 1.0^{*} 10^{-2} \mathrm{~mol}$ ) was added to a 500 $\mathrm{mL}$ round bottom flask with a stir-bar. Approximately $250 \mathrm{~mL}$ of dichloromethane was added followed by six pipettes full of $\mathrm{Br}_{2}$ (approximately 100 equivalents), and the vial was sealed with a Teflon ${ }^{\circledR}$ cap. The reaction mixture was allowed to stir at room temperature for 2 hours at which time TLC analysis indicated the complete consumption of starting material. The excess of bromine was removed using air bubbling and solvent was removed in vacuo to give a crude solid which was slurried in methanol and filtered to give a dark red solid. ${ }^{1} \mathrm{H}$ NMR analysis indicated the presence of minor impurities in the aliphatic region, in order to remove these, the dark red solid was stirred in $\sim 250 \mathrm{~mL}$ hexanes for 30 minutes and filtered to give a red solid. Yield: $6.6 \mathrm{~g}(90 \%)$.

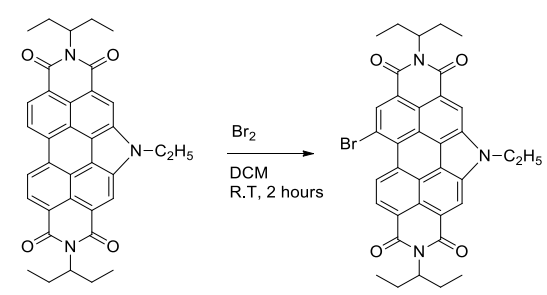

Synthesis of Br-EP-N-Ethyl-CAG-PDI (6b): The synthesis of Br-EP-N-Ethyl-CAG-PDI was carried out in an identical manner to the synthesis of 6 , by substituting the starting material with a hexyl chain (5) for (5b), 
bearing an ethyl chain. Starting with $1 \mathrm{~g}$ of (6b), $1.1 \mathrm{~g}$ of (6b) was obtained, (Yield: $98 \%) .{ }^{1} \mathbf{H}$ NMR (Chloroform-d, TMS/ppm) ס: $10.23\left(\mathrm{~d}, 1 \mathrm{H},{ }^{3} \mathrm{~J}_{\mathrm{H}-\mathrm{H}}=9.5 \mathrm{~Hz}\right), 9.05(\mathrm{~m}, 3 \mathrm{H}), 8.89-8.86(\mathrm{~m}, 1 \mathrm{H}), 5.23-5.21(\mathrm{~m}$ $2 \mathrm{H}), 4.99\left(\mathrm{q}, 2 \mathrm{H},{ }^{3} \mathrm{~J}_{\mathrm{H}-\mathrm{H}}=7.5 \mathrm{~Hz}\right), 2.40-2.33(\mathrm{~m}, 4 \mathrm{H}), 2.05-2.00(\mathrm{~m}, 4 \mathrm{H}), 1.82\left(\mathrm{t}, 3 \mathrm{H},{ }^{3} \mathrm{~J}_{\mathrm{H}-\mathrm{H}}=7.5 \mathrm{~Hz}\right), 1.00(\mathrm{t}, 6 \mathrm{H}$, $\left.{ }^{3} \mathrm{~J}_{\mathrm{H}-\mathrm{H}}=7.5 \mathrm{~Hz}\right), 0.98\left(\mathrm{t}, 6 \mathrm{H},{ }^{3} \mathrm{~J}_{\mathrm{H}-\mathrm{H}}=7.5 \mathrm{~Hz}\right)$.

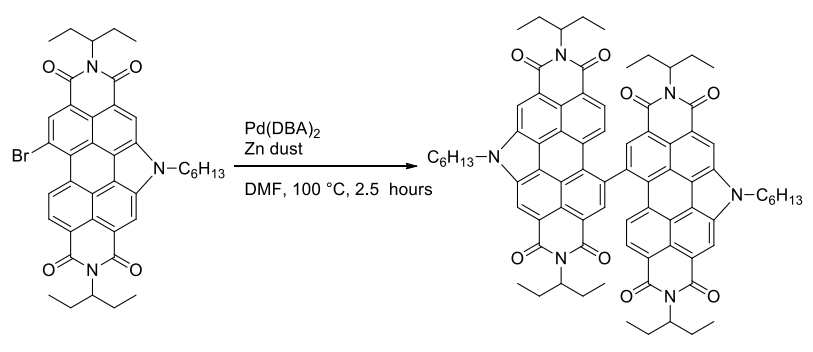

Synthesis of BAY-EP-N-Hex-CAG-PDI (7): The synthesis of BAY-EP-N-Hex-CAG-PDI was carried out using a modified literature procedure. ${ }^{28} \mathrm{Br}$-EP-N-Hex-CAG-PDI ((6), $\left.0.38 \mathrm{~g}, 5.2 * 10^{-4} \mathrm{~mol}\right)$ and Zinc dust (170 mg, $2.6^{*} 10^{-3} \mathrm{~mol}$ ) were added to a $20 \mathrm{~mL}$ microwave vial with a stir-bar. The vial was brought inside the glovebox where approximately $40 \mathrm{mg}$ of bis(dibenzylideneacetone)palladium(0)was added. The vial was sealed under a nitrogen atmosphere using a Teflon ${ }^{\circledR}$ cap and was removed from the glove-box. $20 \mathrm{~mL}$ of $\mathrm{N}^{\prime} \mathrm{N}$ dimethylformamide was added using a syringe and the reaction mixture was purged with nitrogen for 10 minutes. The reaction mixture was heated to $100{ }^{\circ} \mathrm{C}$ for 2.5 hours at which time the reaction had turned a deep blue-purple and TLC analysis indicated the complete consumption of starting material. The reaction mixture was passed through a silica plug to remove solids from the reaction and the solvent was removed in vacuo to give $395 \mathrm{mg}$ of a dark red solid. ${ }^{1} \mathrm{H}$ NMR analysis indicated that the crude product was produced in good yield, however some minor impurities remained in the aromatic region (See Figure S1). The crude solid was loaded on silica gel and purified using column chromatography (hexane to dichloromethane gradient, product elutes at approximately $80 \%$ dichloromethane). The solvent was removed from the product fraction in vacuo resulting in $360 \mathrm{mg}$ of a dark red solid which still contained the same minor impurities in the aromatic region of the ${ }^{1} \mathrm{H}$ NMR spectrum (See Figure S1). To remove these impurities, the red solid was boiled in $100 \mathrm{~mL}$ of iso-propyl alcohol with vigorous stirring for approximately 1 hour, at which time it was allowed to cool to room temperature and filtered using a Buchner funnel, resulting in a bright red solid. Due to the nature of the reaction and the possibility of metal by-product contamination, the material was taken up in dichloromethane, slurried in Celite 545 and passed through an alumina plug. Solvent was removed using a rotary evaporator and the final product was slurried in hot iso-propanol which was then cooled and filtered to give the product as a bright red solid. Yield: $0.16 \mathrm{~g}$ (49\%). ${ }^{1} \mathrm{H}$ NMR (Chloroform-d, TMS/ppm) $\delta:{ }^{1} \mathrm{H}$ NMR (Chloroform-d, TMS/ppm) $\delta$ : $9.26(\mathrm{~s}, 2 \mathrm{H}), 9.08(\mathrm{~s}, 2 \mathrm{H}), 8.89(\mathrm{~s}, 2 \mathrm{H}), 8.00(\mathrm{~s}, 2 \mathrm{H}), 7.76-7.72(\mathrm{~m}, 2 \mathrm{H}), 5.40-4.92(\mathrm{~m}, 4 \mathrm{H}), 4.99-4.81(\mathrm{~m}, 4 \mathrm{H})$, 2.41-2.24 (m, 8H), 2.24-2.09 (m, 4H), 2.05-2.91 (m, 4H), 1.90-1.75 (m, 4H), 1.59-1.50 (m, 4H), 1.47-1.37 $(\mathrm{m}, 4 \mathrm{H}), 1.37-1.29(\mathrm{~m}, 4 \mathrm{H}), 1.03-0.73(\mathrm{~m}, 30 \mathrm{H}) .{ }^{13} \mathrm{C}$ NMR (Chloroform-d, TMS/ppm) $\delta: 140.90,135.28$, 135.06, 132.911,130.40, 126.83, 124.96, 124.72, 123.60, 122.78, 120.11, 119.85, 58.03, 57.64, 47.13, 31.67, 31.44, 27.00, 25.05,22.52, 13.99, 11.50, 11.23. LRMS (APCI). m/z exp: 1253.61 obtained: 1253.84. Melting Point: $380^{\circ} \mathrm{C}$ 

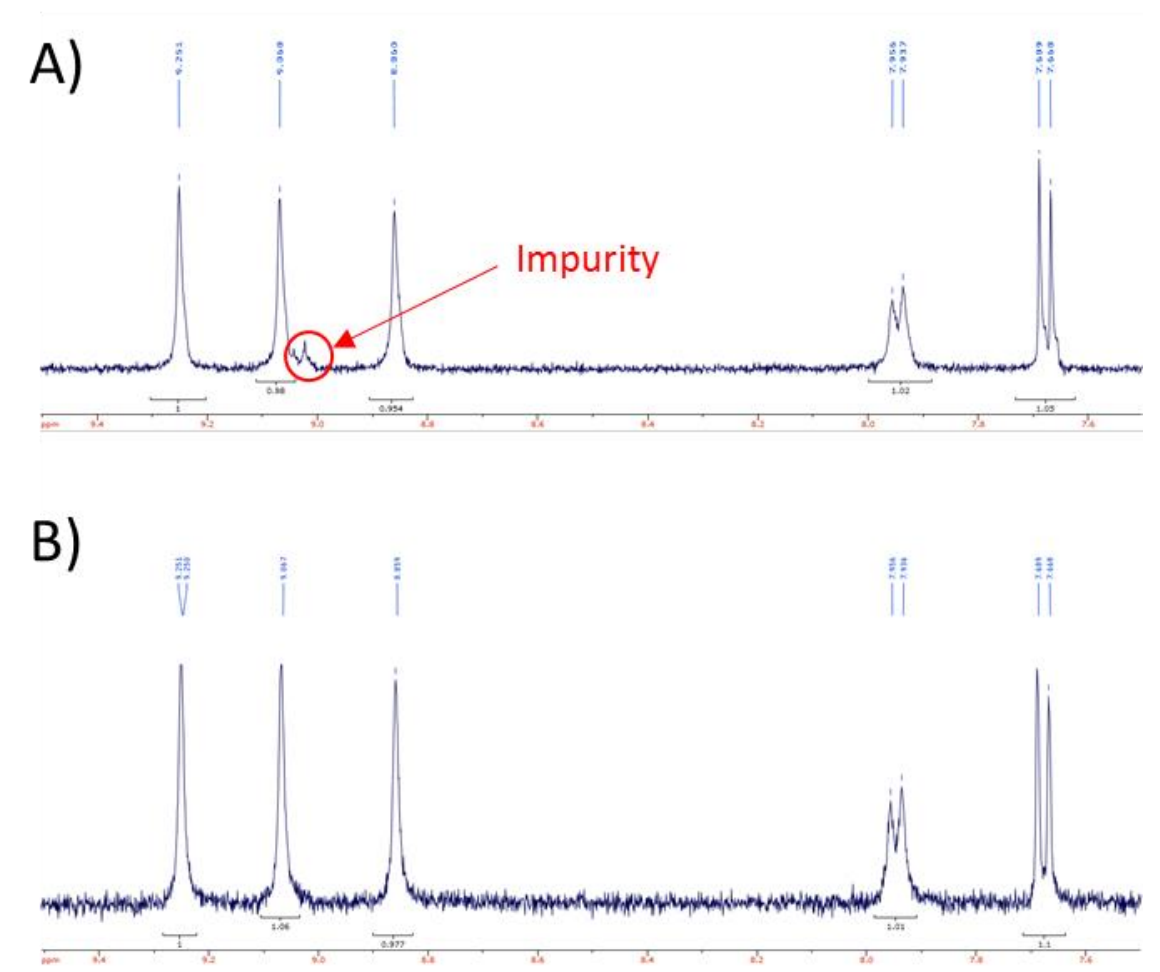

Figure S1: A) ${ }^{1} \mathrm{H}$ NMR spectrum of (7) upon isolation of the crude product. A minor aromatic impurity was present. B) ${ }^{1} \mathrm{H}$ NMR spectrum of (7) after purification using recrystallization from iso-propanol. Full NMR Spectra for all compounds are given in the NMR section of this document.

Scaled up Synthesis of BAY-EP-N-Hex-CAG-PDI (7): The synthesis of BAY-EP-N-Hex-CAG-PDI was carried out using a modified literature procedure. ${ }^{28} \mathrm{Br}$-EP-N-Hex-CAG-PDI ((6), $\left.1.0 \mathrm{~g}, 1.4^{*} 10^{-3} \mathrm{~mol}\right)$ and Zinc dust ( $450 \mathrm{mg}, 6.9 * 10^{-3} \mathrm{~mol}$ ) were added to a $250 \mathrm{~mL}$ Schlenk flask with a stir-bar. The flask was brought inside the glove-box where bis(dibenzylideneacetone)palladium(0)(100 mg, $\left.1.7^{*} 10^{-4} \mathrm{~mol}\right)$ was added. The flask was sealed under a nitrogen atmosphere using a septa and was removed from the glove-box. $100 \mathrm{~mL}$ of $\mathrm{N}, \mathrm{N}^{\prime}$-dimethylformamide was added using a cannula transfer method and the reaction mixture was purged with nitrogen for 10 minutes. The reaction mixture was heated to $100{ }^{\circ} \mathrm{C}$ for 3.5 hours at which time the reaction had turned a deep blue-purple and TLC analysis indicated the complete consumption of starting material. In order to remove organic by-products and residual metal contaminants from the reaction, the reaction was passed through a solid $\mathrm{SiO}_{2}$ support, followed by stirring in dichloromethane with two scoopula tips of Celite ${ }^{\circledR} 545$ for 1 hour and filtration through a second solid support $\left(\mathrm{Al}_{2} \mathrm{O}_{3}\right)$. Solvent was removed in vacuo and the final product was stirred in $\sim 250 \mathrm{~mL}$ boiling iso-propanol which was then slowly cooled to give the product as a bright red solid that could be collected in a Buchner funnel. Yield: $0.69 \mathrm{~g}$ (81\%).

Synthesis of BAY-EP-N-Ethyl-CAG-PDI (7b): The synthesis of BAY-EP-N-Ethyl-CAG-PDI was carried out in an identical manner to the synthesis of (7), by substituting the starting material with a hexyl chain (6) for (6b), bearing an ethyl chain. Starting with $1 \mathrm{~g}$ of (6b) ,0.70 $\mathrm{g}$ of (7b) was obtained. (Yield: $79 \%) .{ }^{1} \mathbf{H}$ NMR (Chloroform-d, TMS/ppm) $\delta$ : $9.29(\mathrm{~s}, 2 \mathrm{H}), 9.11(\mathrm{~s}, 2 \mathrm{H}), 8.88(\mathrm{~s}, 2 \mathrm{H}), 7.97-7.95(\mathrm{~m}, 2 \mathrm{H}), 7.67\left(\mathrm{~d}, 2 \mathrm{H},{ }^{3} \mathrm{~J}_{\mathrm{H}-\mathrm{H}}=\right.$ $8.5 \mathrm{~Hz}), 5.25-5.21(\mathrm{~m}, 2 \mathrm{H}), 5.12\left(\mathrm{q}, 4 \mathrm{H},{ }^{3} \mathrm{~J}_{\mathrm{H}-\mathrm{H}}=7.5 \mathrm{~Hz}\right), 5.02-4.98(\mathrm{~m}, 2 \mathrm{H}), 2.37-2.35(\mathrm{~m}, 4 \mathrm{H}), 2.34-2.18(\mathrm{~m}$, 
4H), 2.04-1.97 (m, 4H), $1.93\left(\mathrm{t}, 6 \mathrm{H},{ }^{3} \mathrm{~J}_{\mathrm{H}-\mathrm{H}}=7.5 \mathrm{~Hz}\right), 1.88-1.82(\mathrm{~m}, 4 \mathrm{H}), 1.01\left(\mathrm{t}, 12 \mathrm{H},{ }^{3} \mathrm{~J}_{\mathrm{H}-\mathrm{H}}=7.5 \mathrm{~Hz}\right), 0.81-1.80$ $(\mathrm{m}, 12 \mathrm{H})$.

Solution ${ }^{1} \mathrm{H}$ and ${ }^{13} \mathrm{C}$ NMR spectra

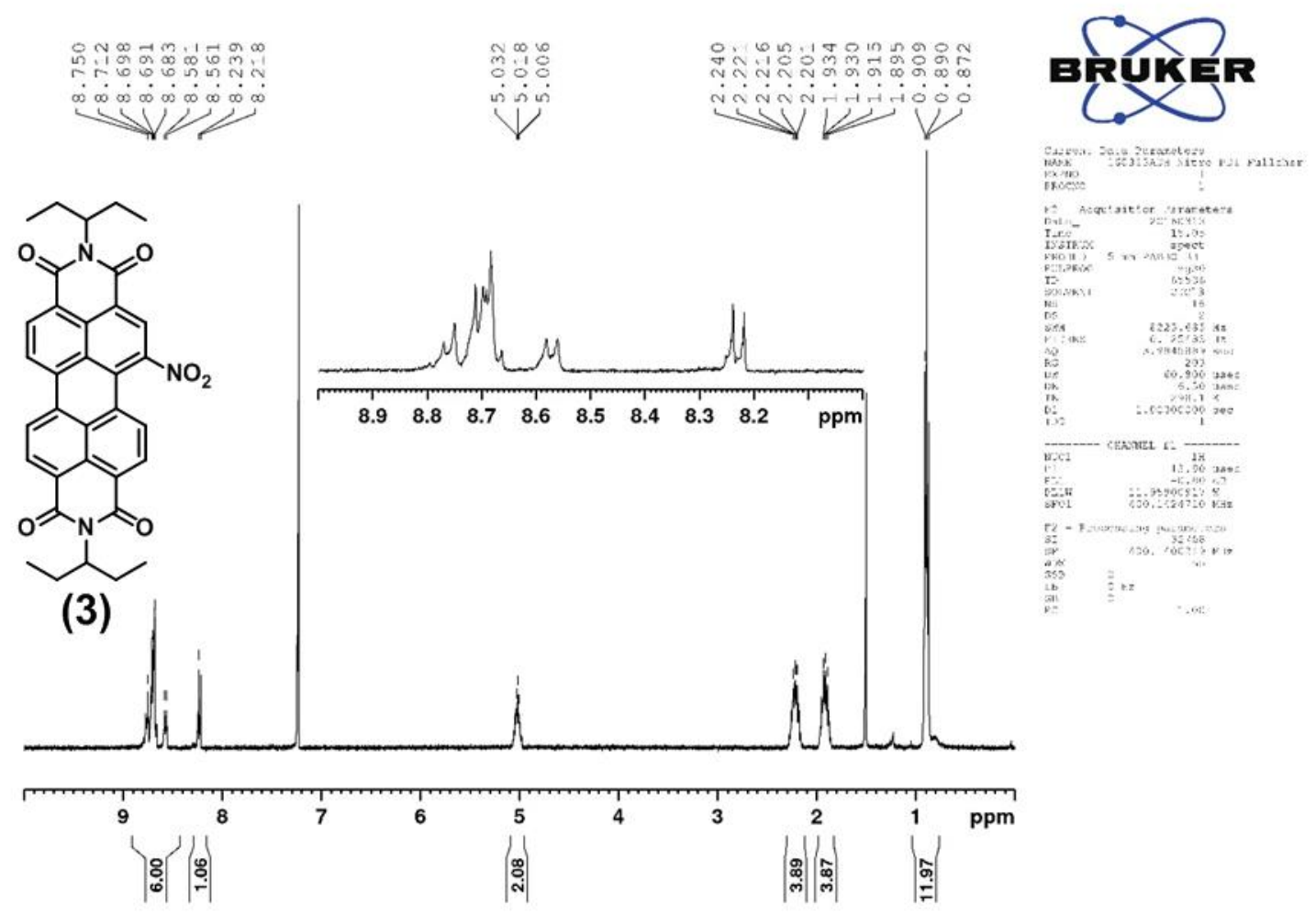

Figure S2: ${ }^{1} \mathrm{H}$ NMR Spectrum of compound (3). 


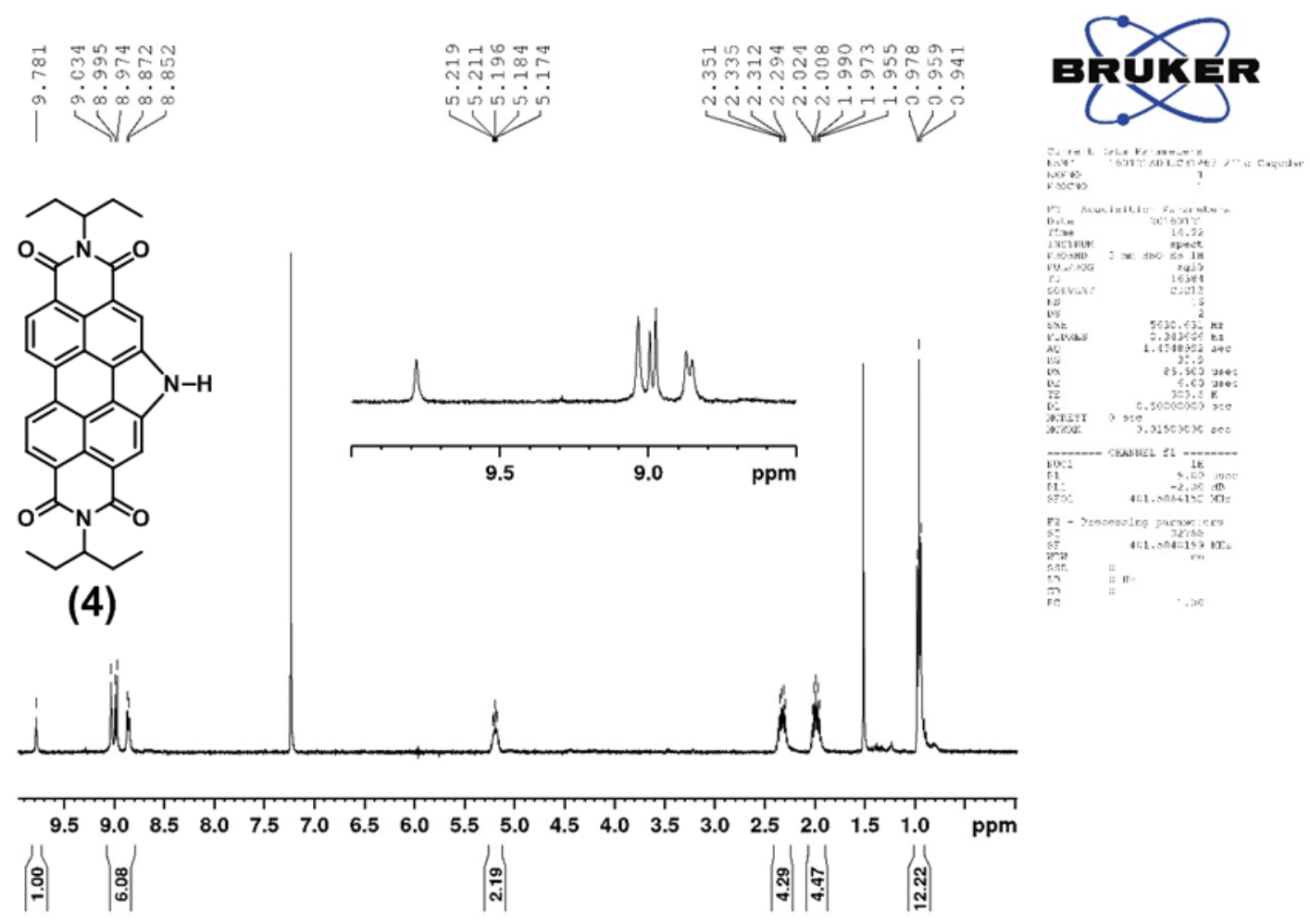

Figure S3: ${ }^{1} \mathrm{H}$ NMR Spectrum of compound (4). 


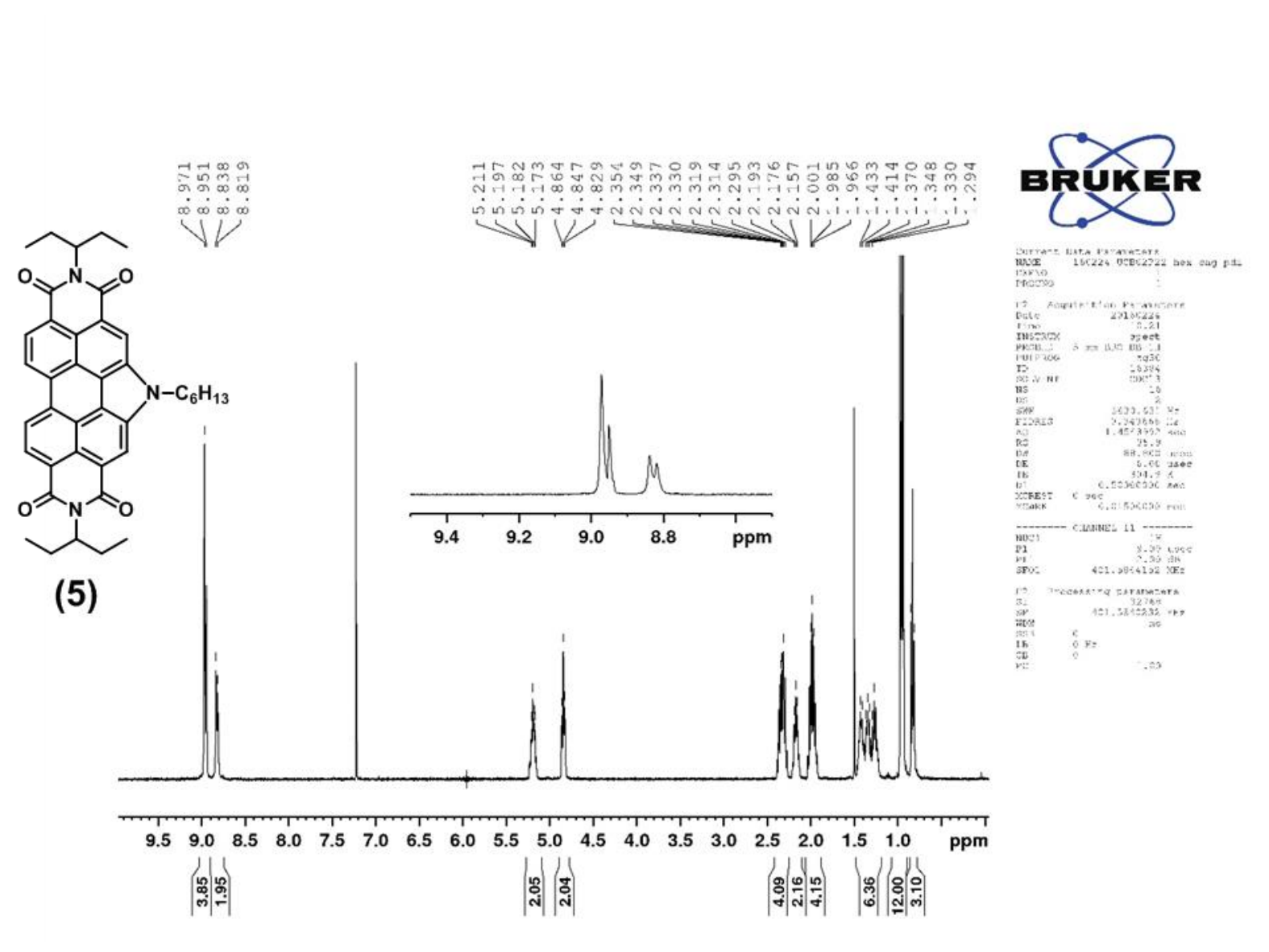

Figure S4: ${ }^{1} \mathrm{H}$ NMR Spectrum of compound (5). 


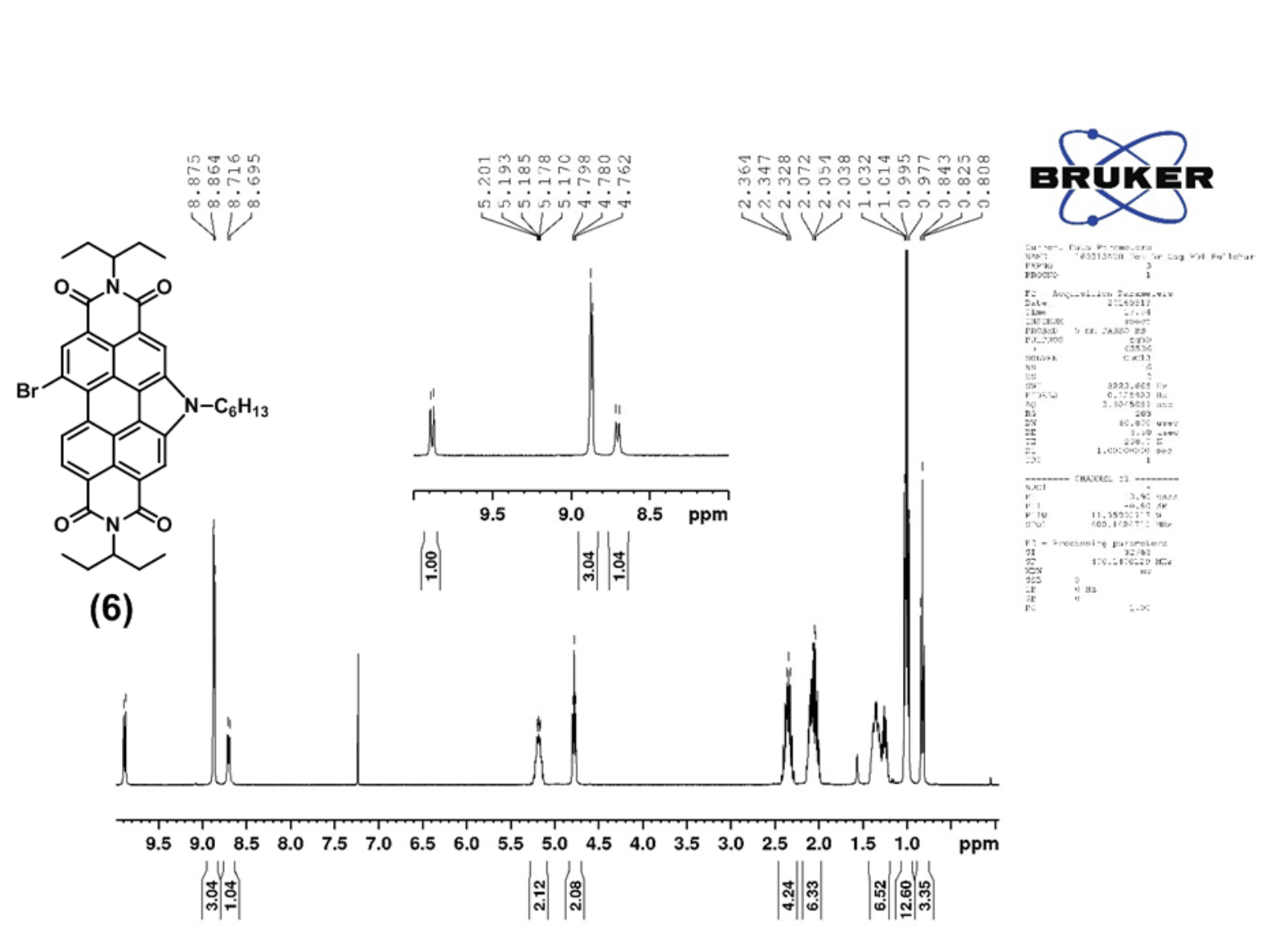

Figure S5: ${ }^{1} \mathrm{H}$ NMR Spectrum of compound (6). 


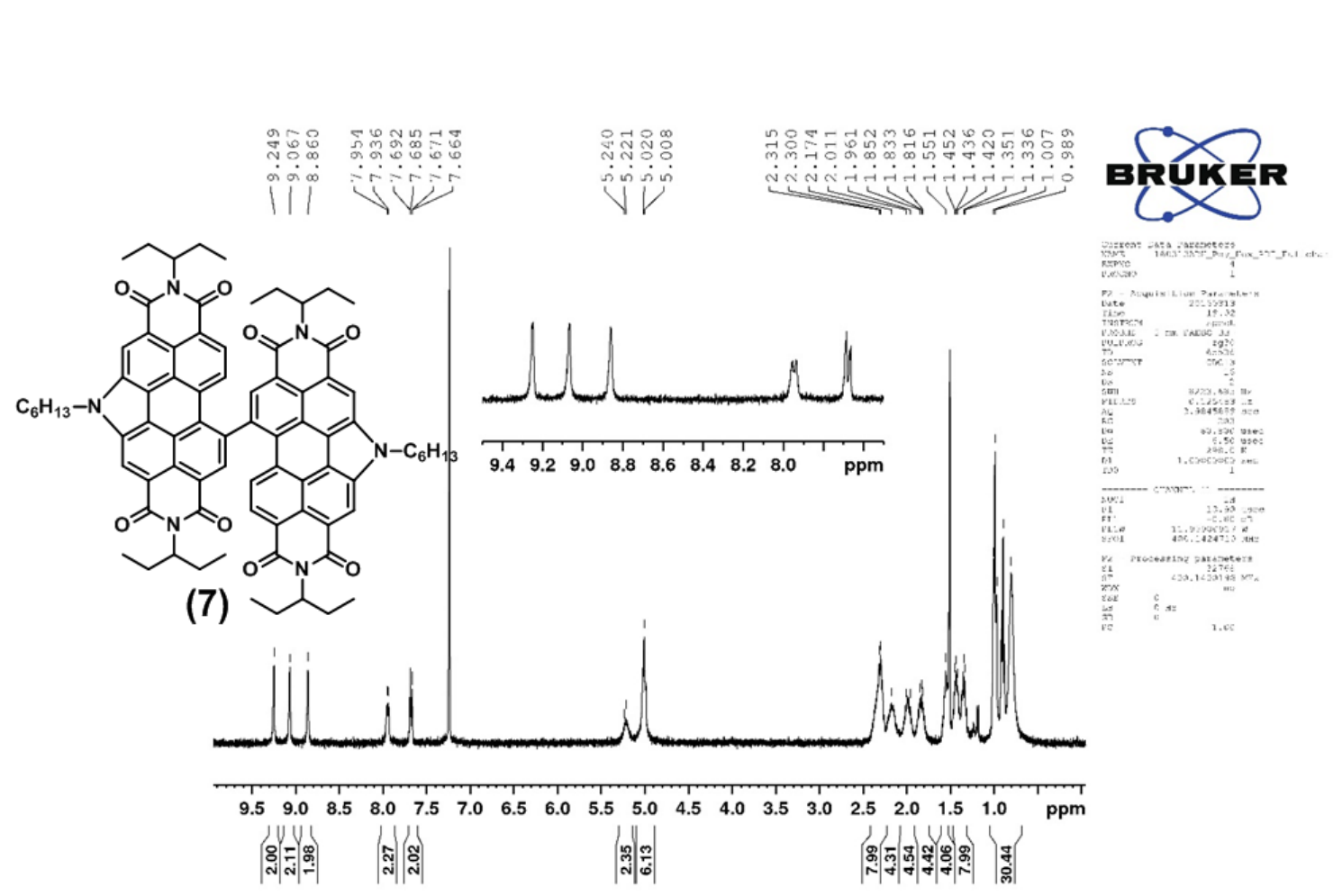

Figure S6: ${ }^{1} \mathrm{H}$ NMR Spectrum of compound (7). 


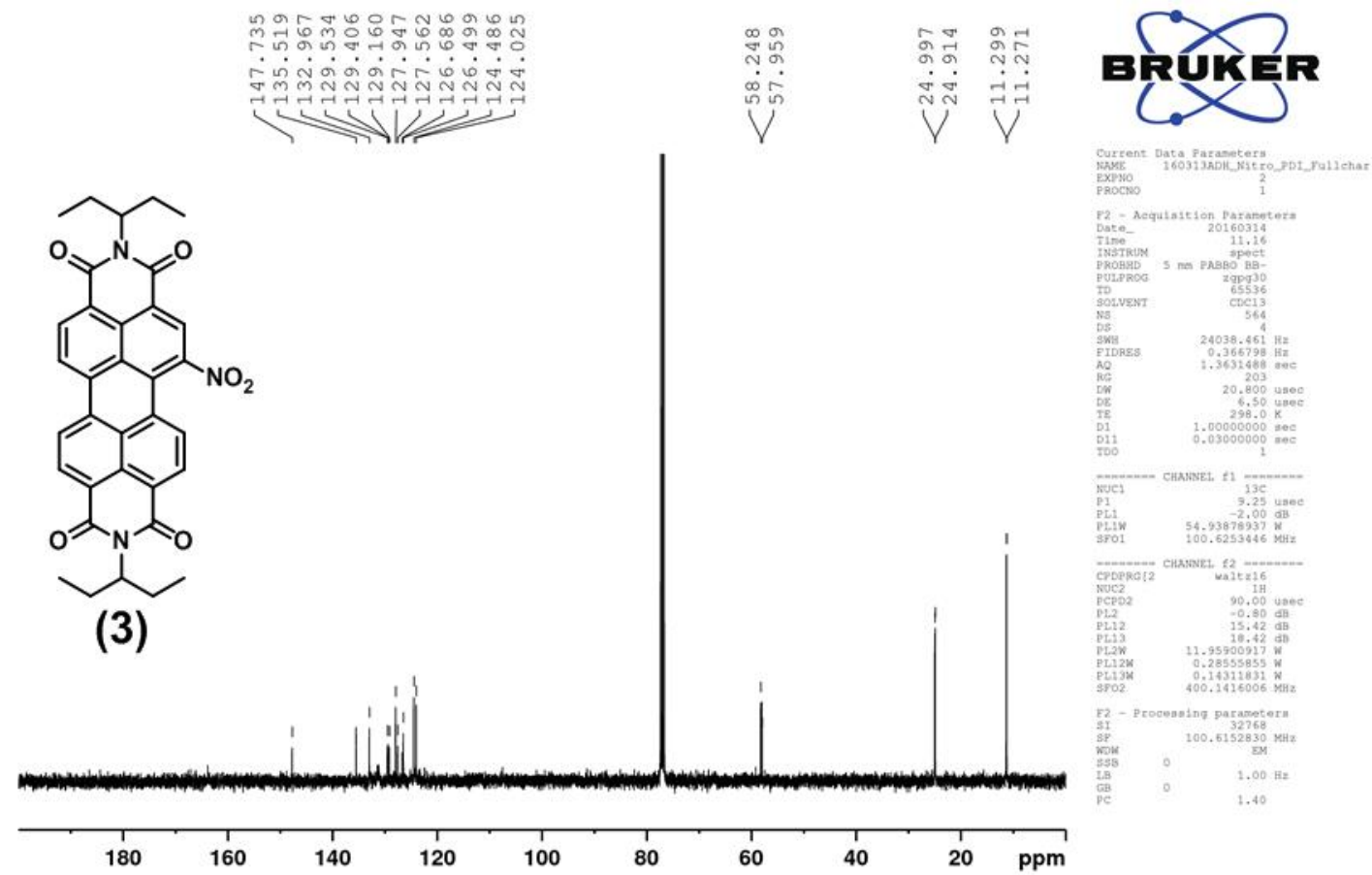

Figure S7: ${ }^{13} \mathrm{C}$ NMR Spectrum of compound (3).

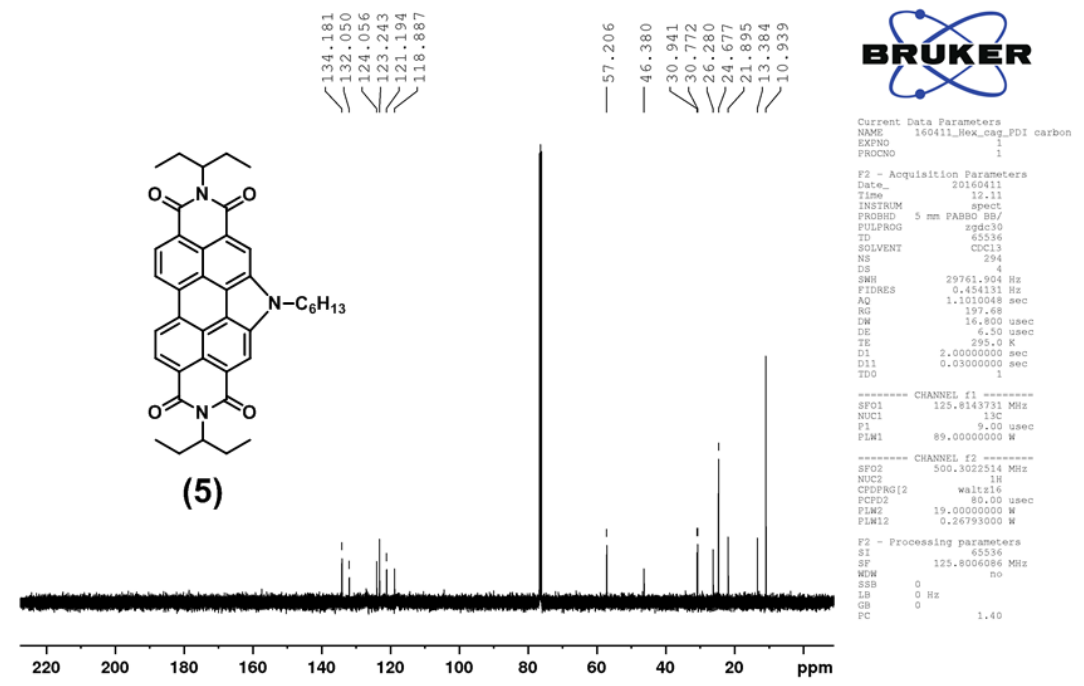

Figure S8: ${ }^{13} \mathrm{C}$ NMR Spectrum of compound (5). 


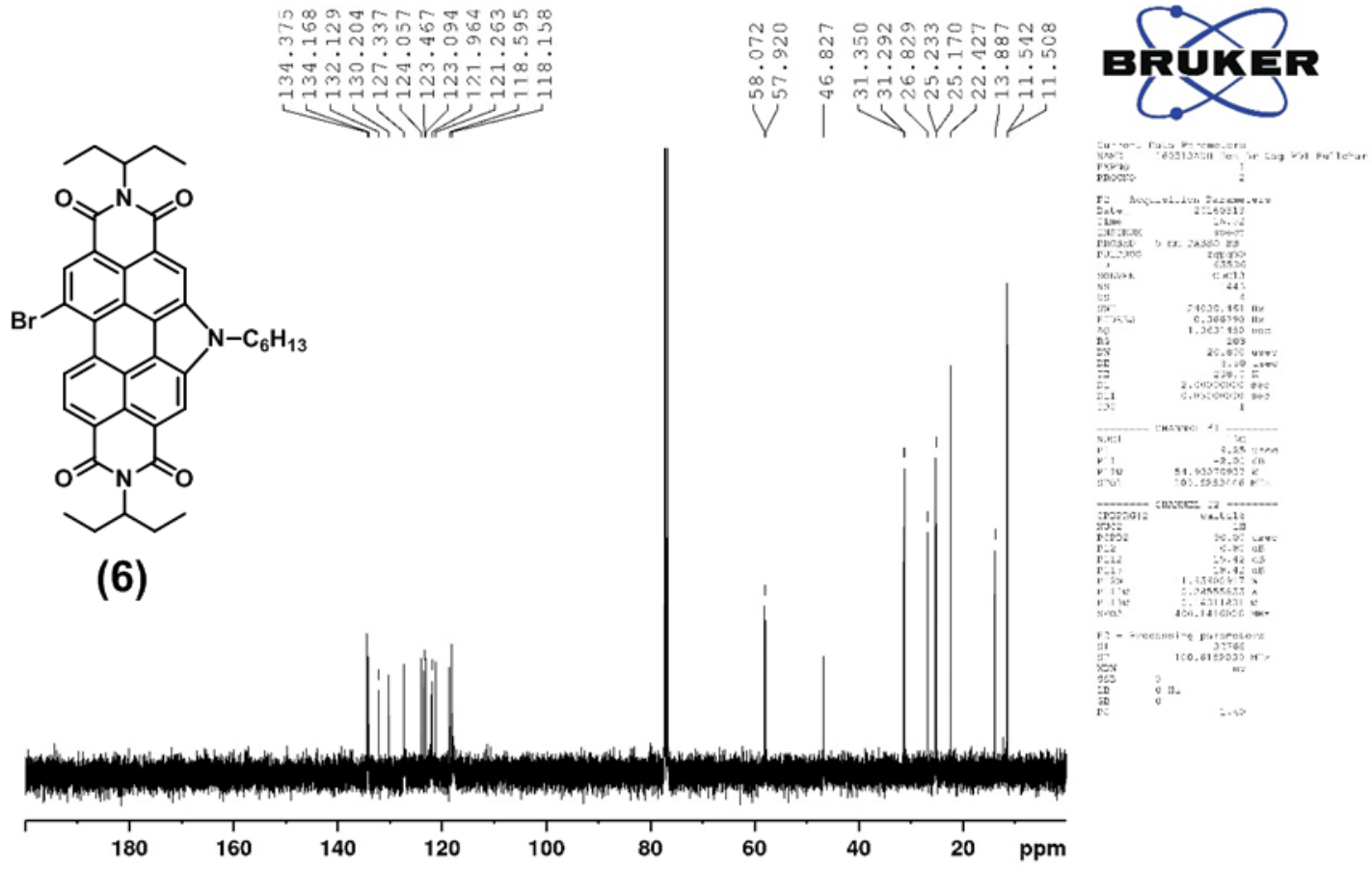

Figure S8: ${ }^{13} \mathrm{C}$ NMR Spectrum of compound (6). 


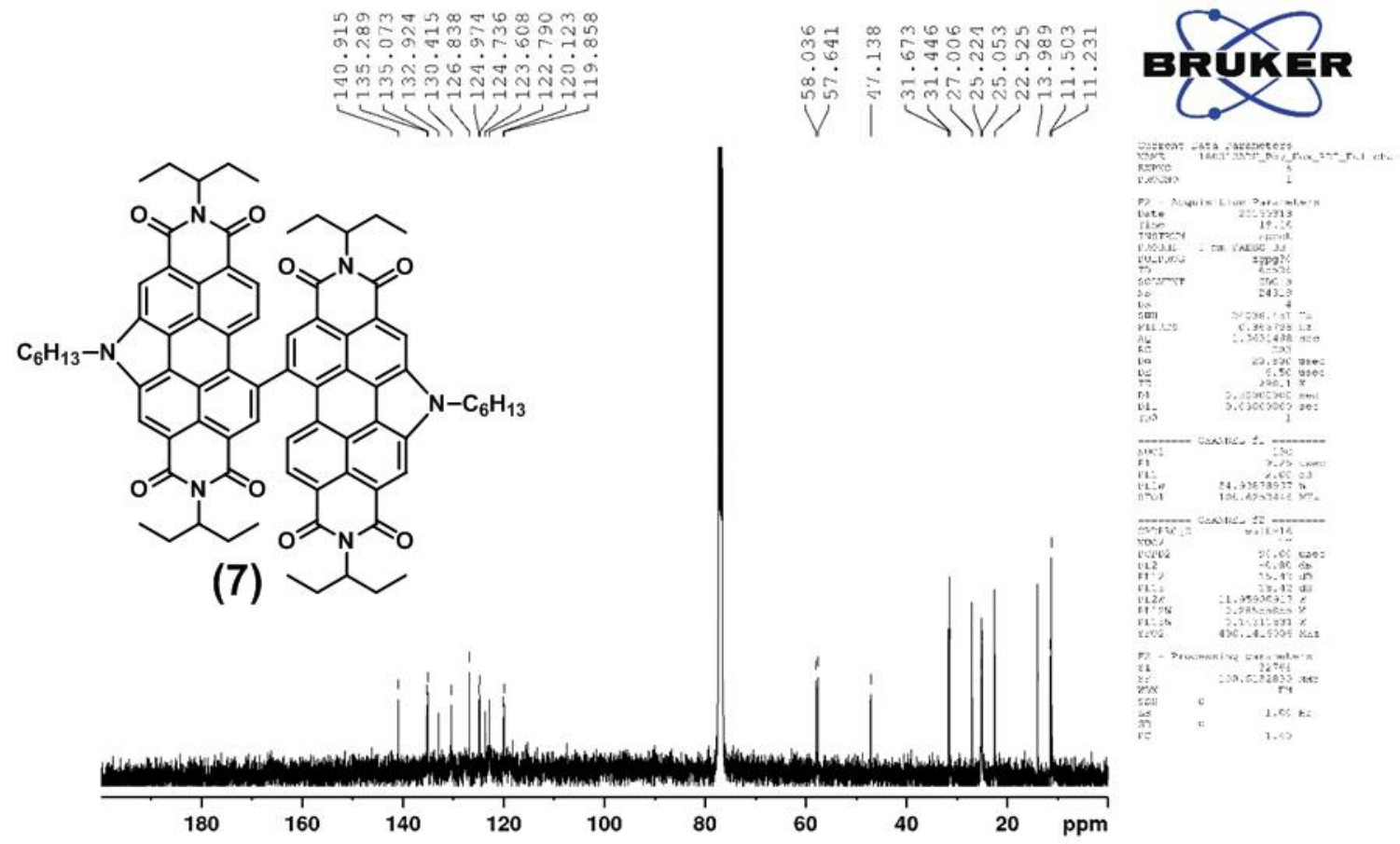

Figure S9: ${ }^{13} \mathrm{C}$ NMR Spectrum of compound (7). 


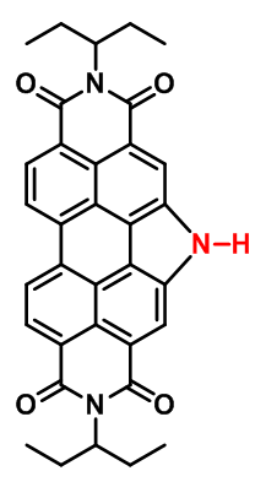

(4)

$20 \mathrm{mg} / \mathrm{mL}$

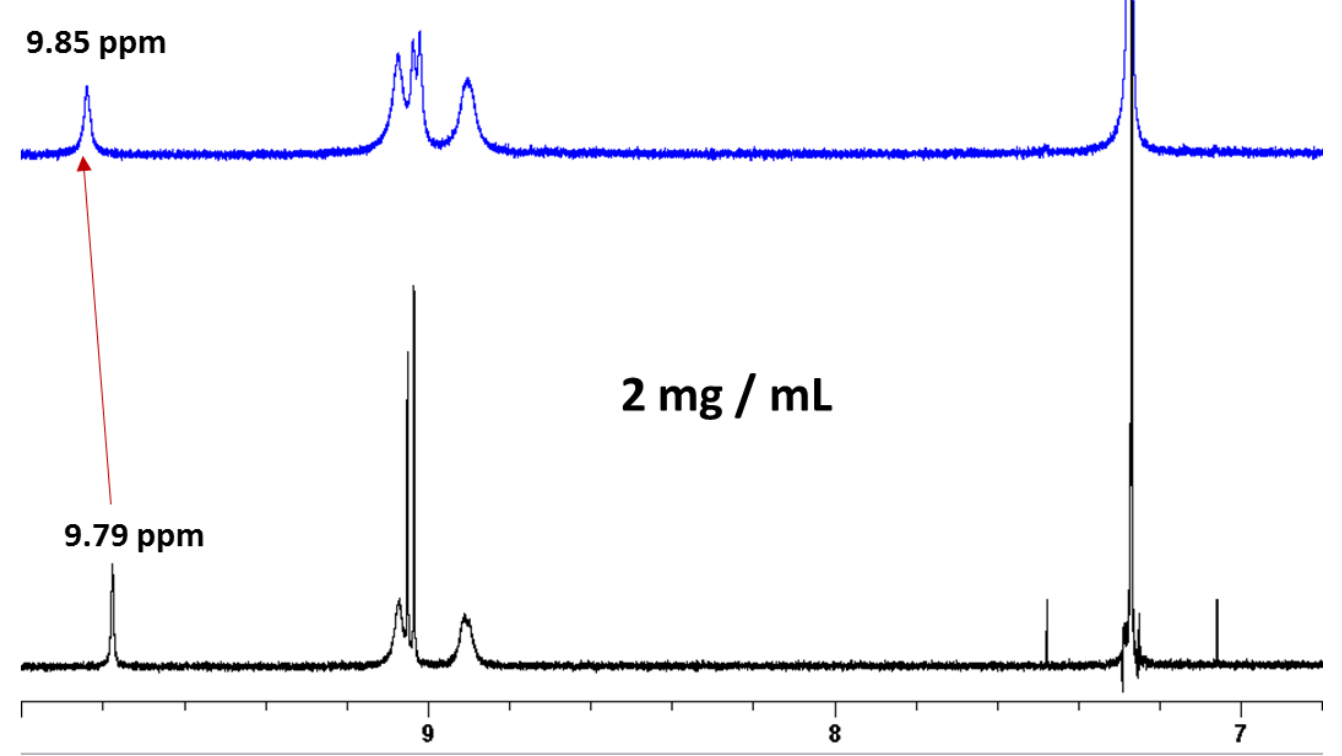

Figure S10: ${ }^{1} \mathrm{H}$ NMR Spectra of (4) at two different concentrations, showing the shift in the $\mathrm{N}-\mathrm{H}$ resonance, possibly due to de-shielding of the proton from a hydrogen bonding interaction. 


\section{Solubility Curves.}

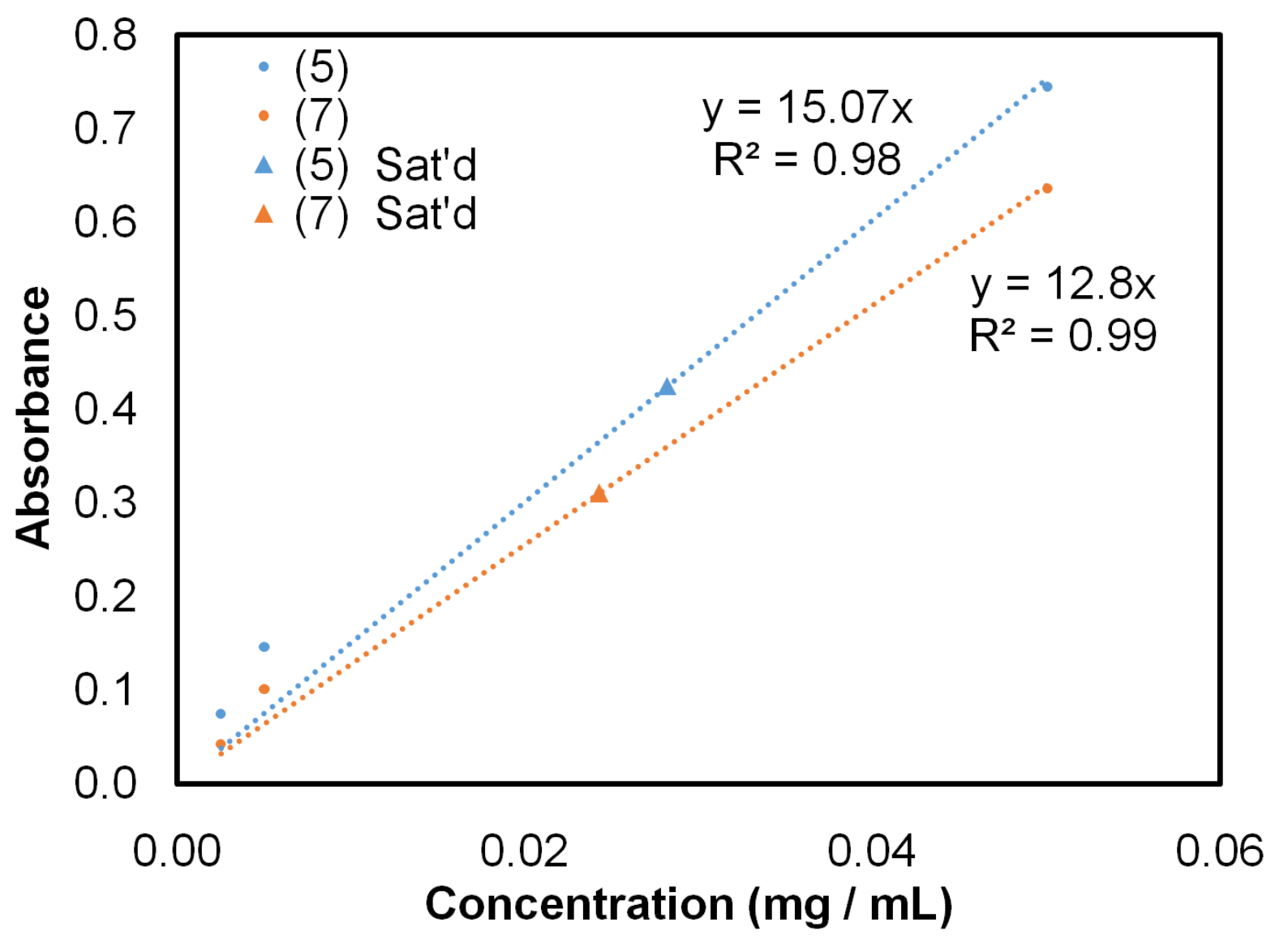

Figure S11: Concentration vs absorption plot for determining the solubility of compounds (5) and (7). A calibration curve was made for each compound by plotting absorbance values of known concentrations. (Dotted lines). In order to determine solubility, compounds (5) and (7) were made into solutions having $50 \mathrm{mg} / \mathrm{mL}$ concentration, allowed to stir overnight and then passed through a $0.45 \mu \mathrm{m}$ syringe filter to remove any undissolved solids. The obtained solutions were then diluted by a factor of 2000 so that their absorbance was in the range of values used for the calibration curves. By using the Beer-Lambert law and the slope of the respective curves, it was determined that the solubility of both (5) and (7) was $\sim 50 \mathrm{mg} / \mathrm{mL}$. This observation is confirmed by the apparent complete dissolution of $50 \mathrm{mg} / \mathrm{mL}$ samples of either (5) or (7) in $\mathrm{CHCl}_{3}$. 
Table S1: Solubility curve data in $\mathrm{CHCl}_{3}$ for compounds (5) and (7) used to plot solubility curves.

\begin{tabular}{|c|c|c|c|c|}
\hline Compound (7) & & & & \\
\hline Solution & Concentration $(\mathrm{mg} / \mathrm{mL})$ & Abs (@532 nm) & Slope & Molarity \\
\hline Cal2 & 0.0500 & 0.636 & 12.8 & $3.99 \mathrm{E}-05$ \\
\hline Cal3 & 0.0050 & 0.101 & & $3.99 \mathrm{E}-06$ \\
\hline Cal4 & 0.0025 & 0.042 & & $1.99 \mathrm{E}-06$ \\
\hline Satd & 0.0243 & 0.310 & & $1.94 \mathrm{E}-05$ \\
\hline Satd Back Diluted & 48.5 & & & $3.87 \mathrm{E}-02$ \\
\hline \multicolumn{5}{|l|}{ Compound (5) } \\
\hline Solution & Concentration $(\mathrm{mg} / \mathrm{mL})$ & Abs (@529 nm) & Slope & Molarity \\
\hline Cal2 & 0.0500 & 0.745 & 15.1 & $7.62 \mathrm{E}-05$ \\
\hline Cal3 & 0.0050 & 0.146 & & $7.62 \mathrm{E}-06$ \\
\hline Cal4 & 0.0025 & 0.075 & & $3.81 \mathrm{E}-06$ \\
\hline Satd & 0.0281 & 0.425 & & $3.70 \mathrm{E}-05$ \\
\hline Satd Back Diluted & 56.3 & & & $7.40 \mathrm{E}-02$ \\
\hline
\end{tabular}




\section{Mass Spectrometry}

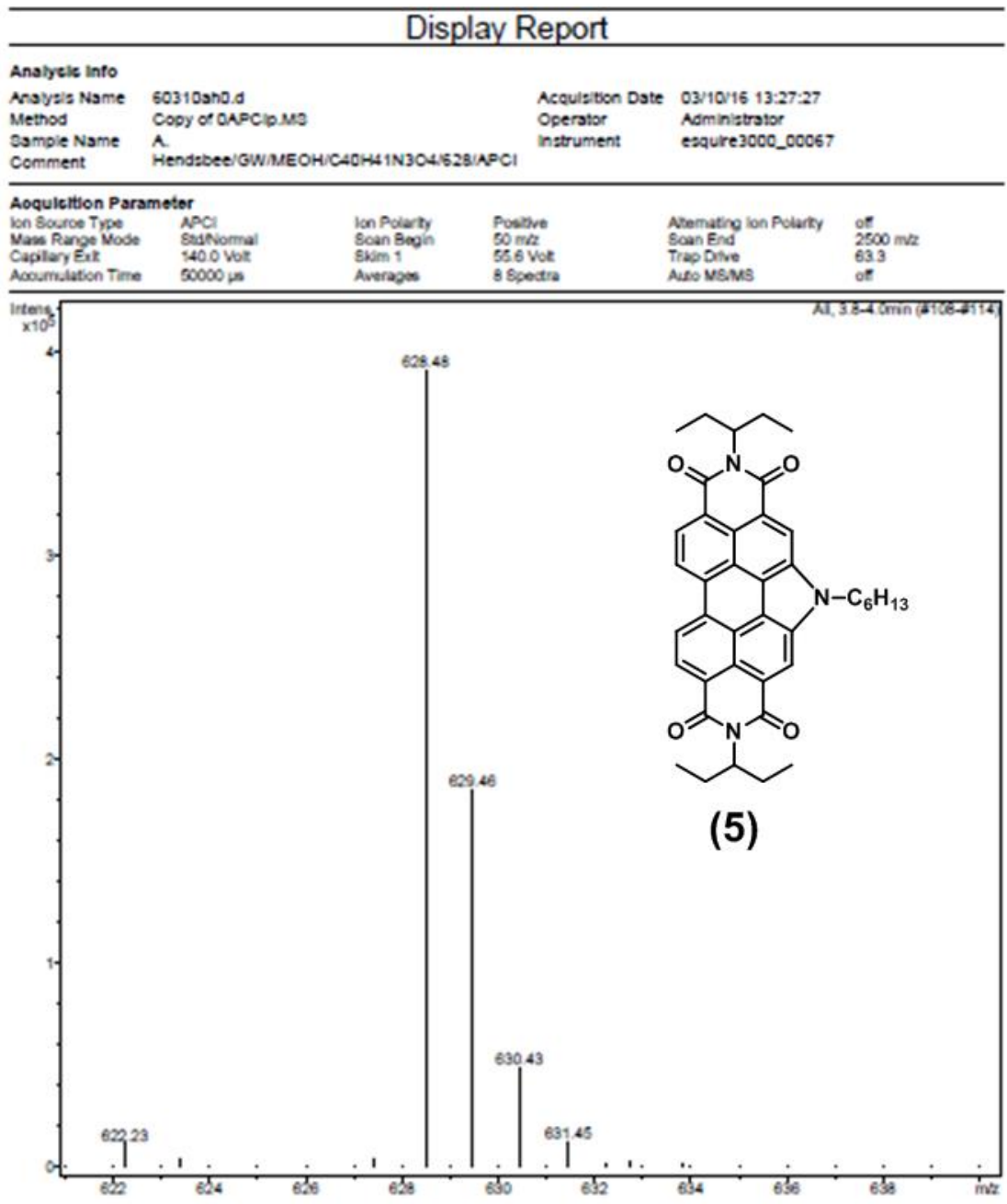

Eruker Datonica Dataqnatyala 3.0

Prnted: 03/10/16 13:35:50

Pope 1 of 1

Figure S12: Mass Spectrum of (5). 


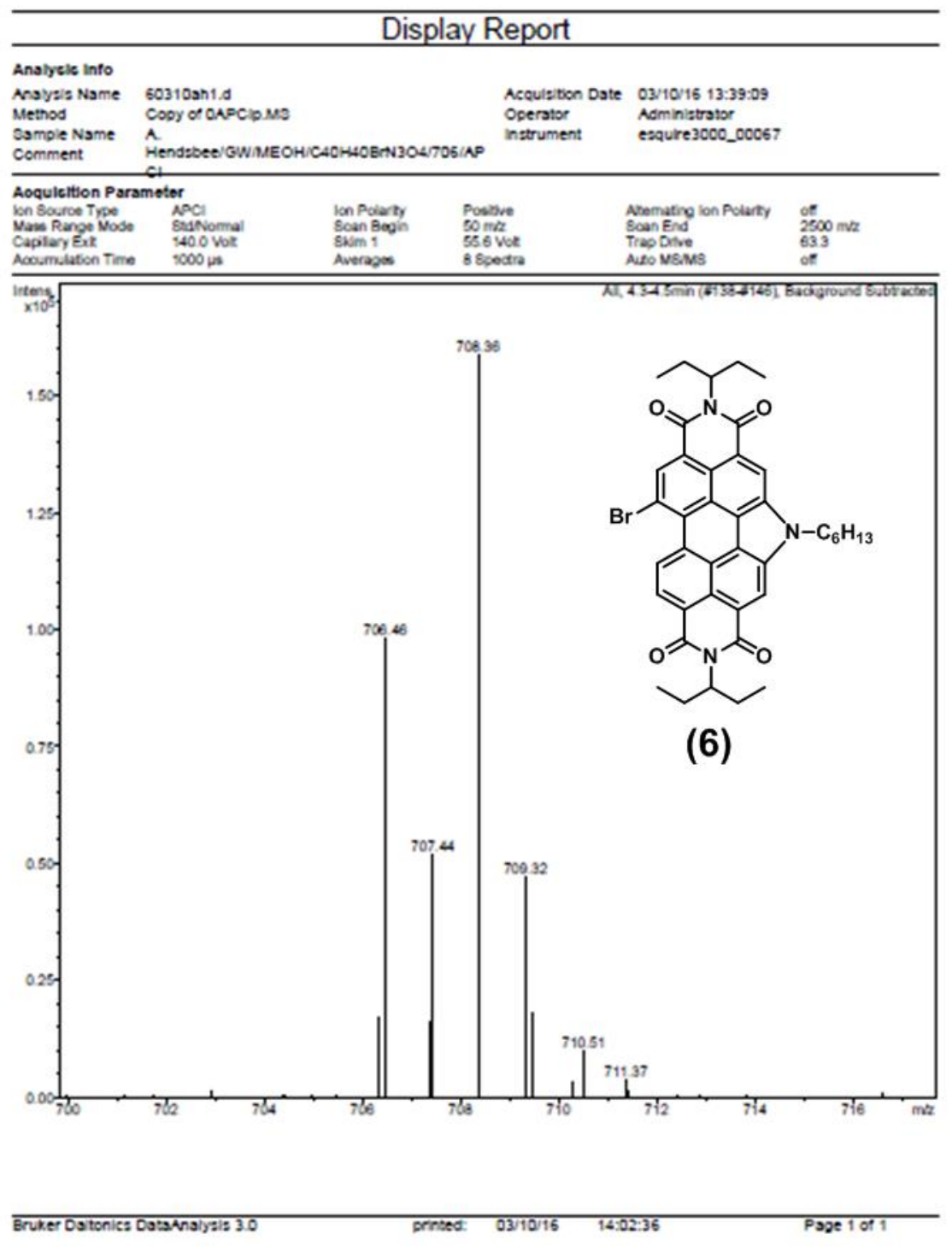

Figure S13: Mass Spectrum of (6). 


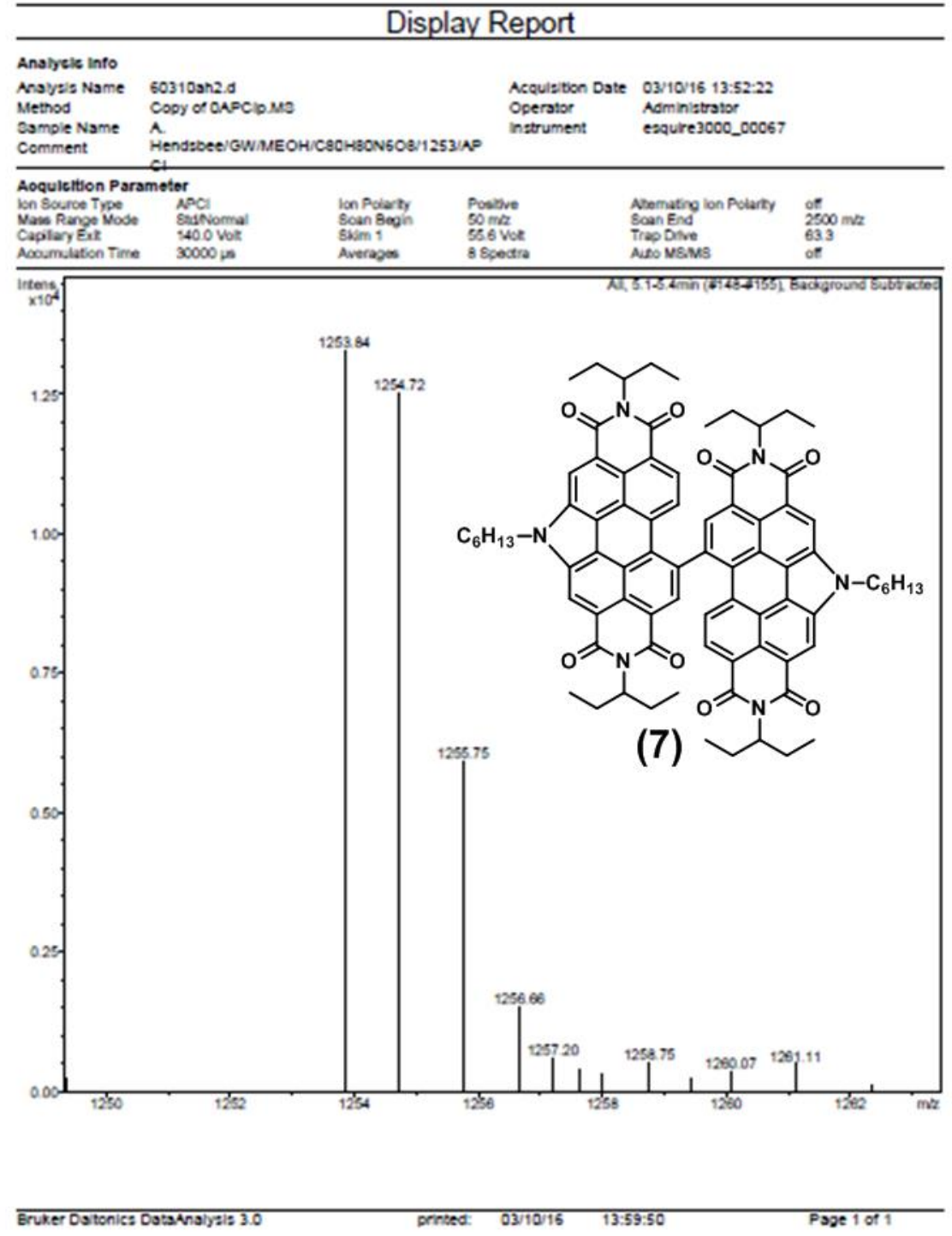

Figure S14: Mass spectrum of (7). 
DFT Calculations:

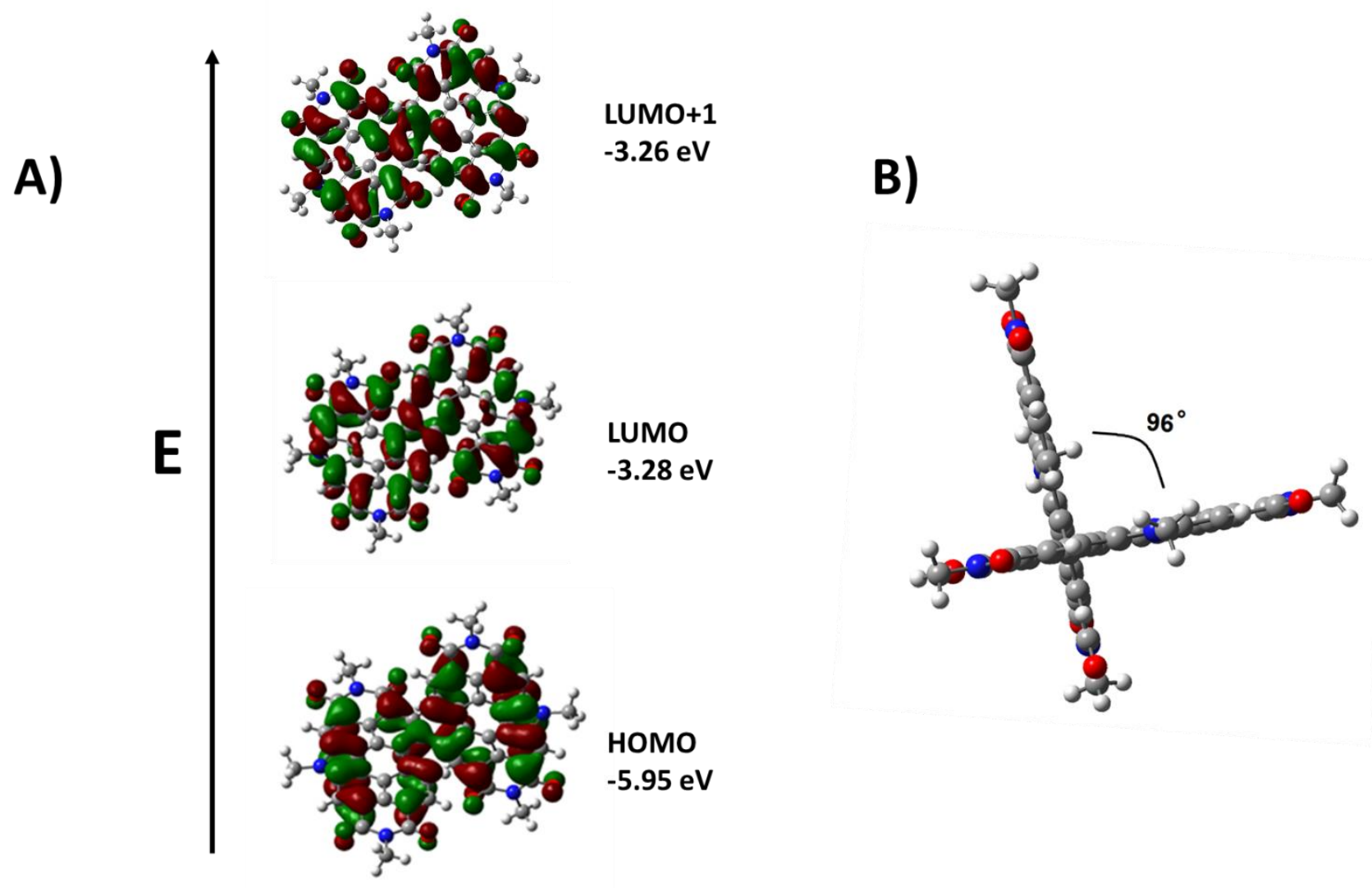

Figure S15: DFT calculations for compound (7). A) Frontier molecular orbitals. B) Optimized geometry. 


\section{Details on Device Fabrication of Organic Solar Cells using PTB7 or PTB7-Th (Hill)}

Patterned indium tin oxide (ITO) (Thin Film Devices, 15-20 $\Omega / \square$ ) on glass substrates $(25 \times 25 \mathrm{~mm}$ ) were cleaned in an ultrasonic bath beginning with deionized water and detergent, followed by deionized water, acetone, and ethanol. The substrates were blown dry with air and underwent 20 minutes of UV-ozone treatment. Next, zinc oxide precursor solution $(100 \mathrm{mg} / \mathrm{mL}$ zinc acetate dehydrate in 2-methoxyethanol with $2.8 \% \mathrm{v} / \mathrm{v}$ ethanolamine) was spin-cast at $4000 \mathrm{rpm}$ in air and annealed at $200{ }^{\circ} \mathrm{C}$ for 60 minutes. The hot substrates were transferred to a $\mathrm{N}_{2}$ glovebox for active-layer casting. The active layers of the devices were cast from filtered solutions of polymer:PDI (polymer = PTB7, PTB7-Th, 1 Material) in the specified weight ratios with total dye loading of $25 \mathrm{mg} / \mathrm{mL}$ in chlorobenzene with the specified amount of 1,8diiodooctane (DIO) additive. Active layers were spun at $1500 \mathrm{rpm}$. The $\mathrm{MoO}_{3}$ anode interlayer (15 nm) was thermally evaporated under vacuum $\left(10^{-6} \mathrm{mbar}\right)$. Finally, $100 \mathrm{~nm}$ of $\mathrm{Ag}$ was thermally evaporated through a shadow mask under vacuum $\left(10^{-6} \mathrm{mbar}\right)$ to form the anode. Each substrate contained 18 devices with active areas of $0.0325 \mathrm{~cm}^{2}$. The current density vs. voltage characteristics were measured using a Keithley 236 source-measure unit while the devices were illuminated with a solar simulator (ScienceTech SS0.5kW) outputting an AM $1.5 \mathrm{G}$ spectrum at $100 \mathrm{~mW} / \mathrm{cm}^{2}$ intensity. The solar simulator intensity was measured using a calibrated Si photodiode and a KG5 filter.

Electron-only diodes were fabricated by casting neat films of 5,7 , and $7 \mathrm{~b}$ onto ITO/ZnO substrates, with two film thicknesses for each compound. Top contacts consisting of Ca (15 nm), followed by Ag (100 nm) were thermally evaporated under vacuum $\left(10^{-6} \mathrm{mbar}\right)$ through a shadow mask. The current density vs. voltage characteristics were measured as stated above, except under dark conditions. Film thicknesses were measured using a Veeco Dektak 8 profilometer.

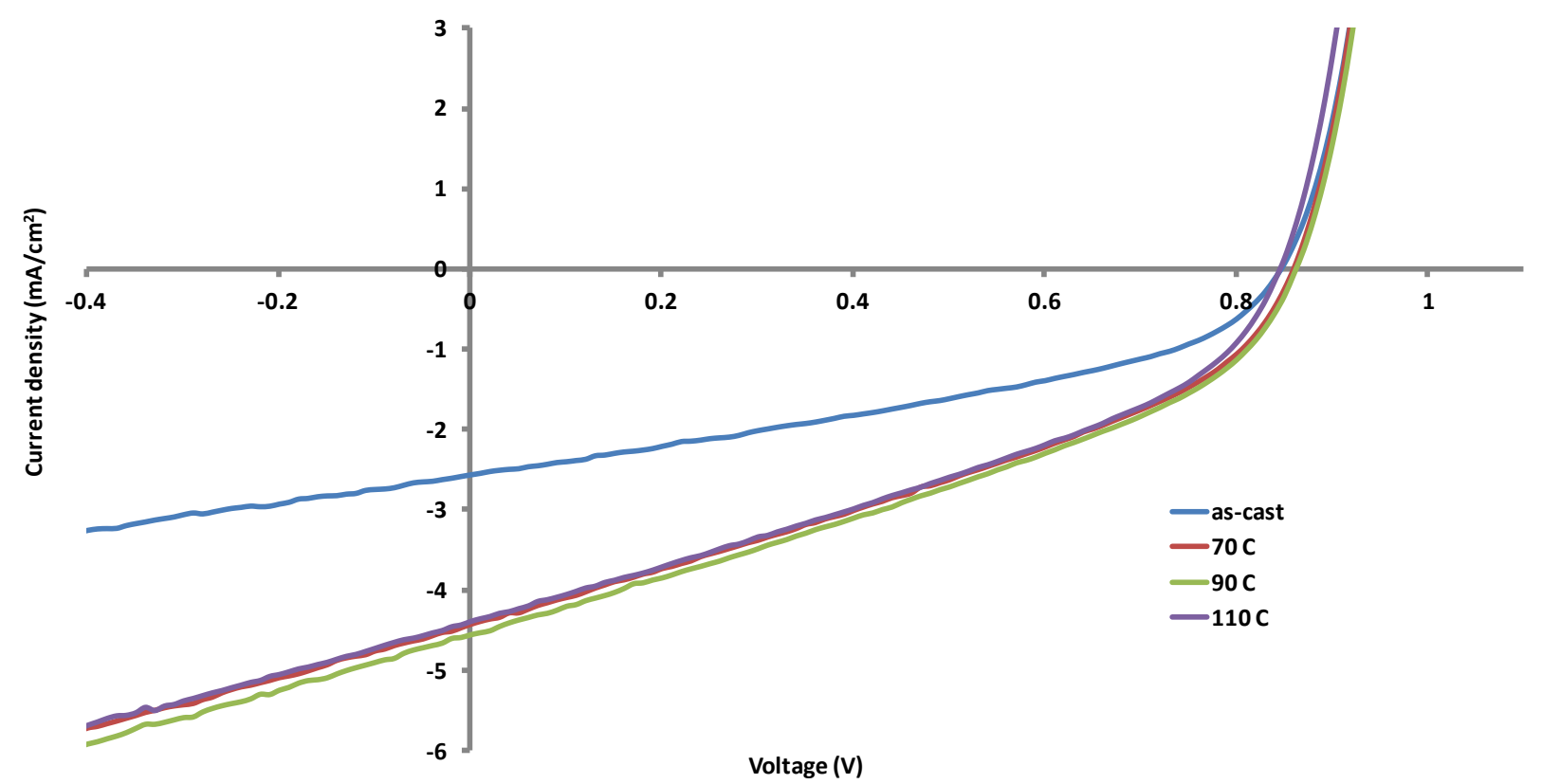

Figure S16: Current density-voltage (JV) curves of PTB7:(7) using a 50:50 blend ratio and thermal annealing. 
Table S2: Photovoltaic performance metrics of PTB7:(7) using a 50:50 blend ratio and thermal annealing.

\begin{tabular}{lrrrrl} 
annealing temperature & Voc $(\mathrm{V})$ & $\begin{array}{r}\text { JsC } \\
\left(\mathrm{mA} / \mathrm{cm}^{\wedge} 2\right)\end{array}$ & PCE (\%) & FF & \\
\hline as cast & 0.83 & 2.46 & 0.79 & 0.39 & avg. \\
& $\mathbf{0 . 8 5}$ & $\mathbf{2 . 5 7}$ & $\mathbf{0 . 8 4}$ & $\mathbf{0 . 3 9}$ & best \\
$70 \mathrm{C}$ & 0.83 & 4.10 & 1.18 & 0.35 avg. \\
& $\mathbf{0 . 8 6}$ & $\mathbf{4 . 4 2}$ & $\mathbf{1 . 3 3}$ & $\mathbf{0 . 3 5}$ best \\
$90 \mathrm{C}$ & 0.87 & 4.37 & 1.32 & 0.35 avg. \\
& $\mathbf{0 . 8 6}$ & $\mathbf{4 . 6 0}$ & $\mathbf{1 . 4 0}$ & $\mathbf{0 . 3 5}$ best \\
$110 \mathrm{C}$ & 0.89 & 4.07 & 1.24 & 0.35 avg. \\
& $\mathbf{0 . 8 5}$ & $\mathbf{4 . 3 9}$ & $\mathbf{1 . 3 2}$ & $\mathbf{0 . 3 6}$ best \\
\hline
\end{tabular}

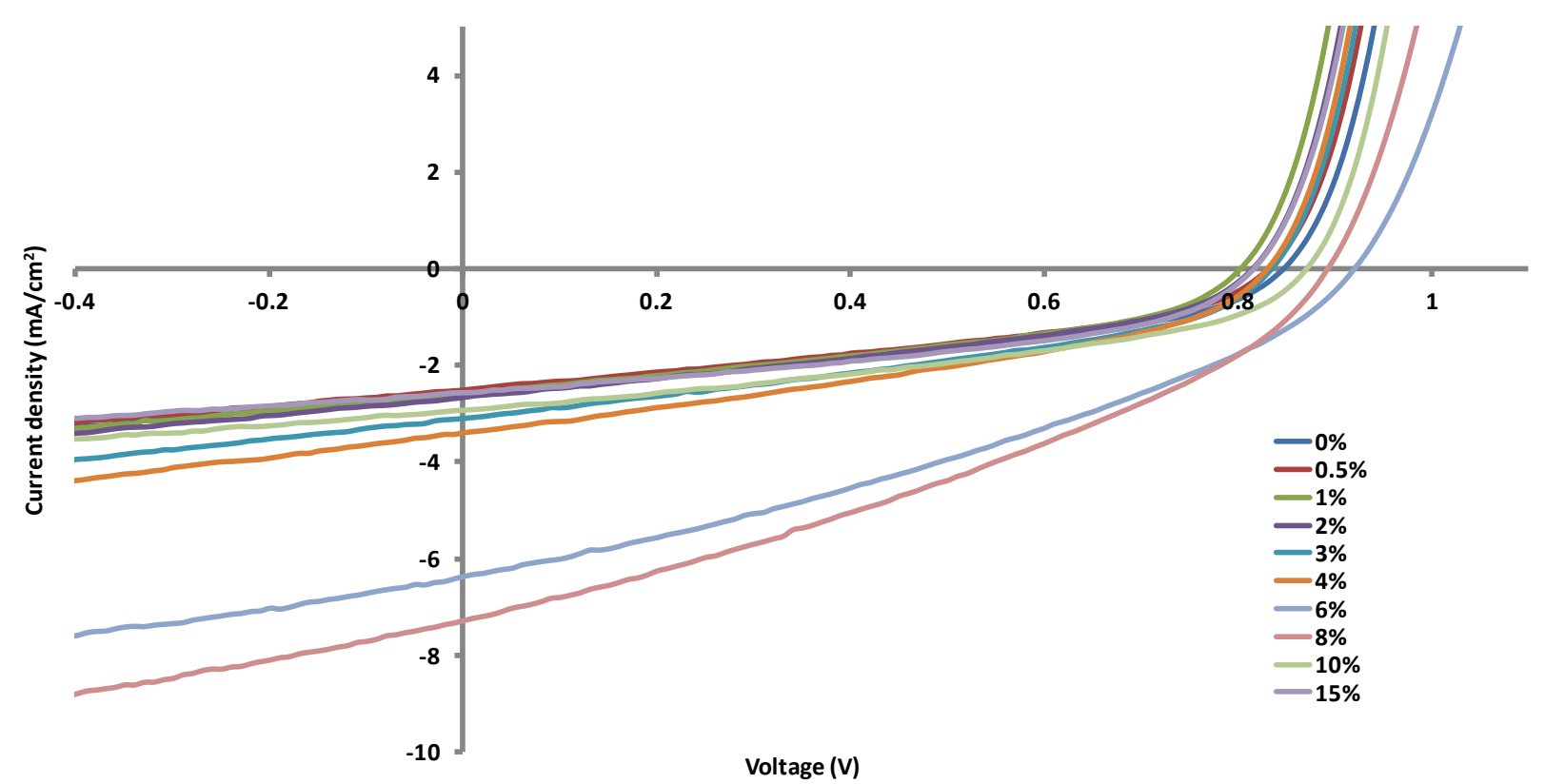

Figure S17: Current density-voltage (JV) curves of PTB7:(7) using a 50:50 blend ratio and varying the DIO additive.

Table S3: Photovoltaic performance metrics of PTB7:(7) using a 50:50 blend ratio and varying the DIO additive.

\begin{tabular}{rrrrrrl} 
DIO additive (\% v/v) & & Voc $(\mathrm{V})$ & $\begin{array}{r}\text { JsC } \\
\left(\mathrm{mA} / \mathrm{cm}^{\wedge} 2\right)\end{array}$ & PCE (\%) & FF & \\
\hline & 0 & 0.83 & 2.46 & 0.79 & 0.39 & avg. \\
& 0.85 & $\mathbf{2 . 5 7}$ & $\mathbf{0 . 8 4}$ & $\mathbf{0 . 3 9}$ & best \\
& 0.5 & 0.81 & 2.35 & 0.75 & 0.39 avg.
\end{tabular}




\begin{tabular}{|c|c|c|c|c|c|}
\hline & 0.83 & 2.52 & 0.81 & 0.39 & best \\
\hline \multirow[t]{2}{*}{1} & 0.79 & 2.50 & 0.78 & 0.39 & avg. \\
\hline & 0.80 & 2.58 & 0.81 & 0.39 & best \\
\hline \multirow[t]{2}{*}{2} & 0.80 & 2.62 & 0.80 & 0.39 & avg. \\
\hline & 0.81 & 2.66 & 0.83 & 0.38 & best \\
\hline \multirow[t]{2}{*}{3} & 0.82 & 3.02 & 0.94 & 0.38 & avg. \\
\hline & 0.83 & 3.10 & 0.98 & 0.38 & best \\
\hline \multirow[t]{2}{*}{4} & 0.82 & 3.11 & 0.96 & 0.38 & avg. \\
\hline & 0.83 & 3.40 & 1.04 & 0.37 & best \\
\hline \multirow[t]{2}{*}{6} & 0.89 & 6.23 & 1.85 & 0.33 & avg. \\
\hline & 0.92 & 6.38 & 2.01 & 0.34 & best \\
\hline \multirow[t]{2}{*}{8} & 0.90 & 6.87 & 2.11 & 0.34 & avg. \\
\hline & 0.89 & 7.29 & 2.21 & 0.34 & best \\
\hline \multirow[t]{2}{*}{10} & 0.84 & 2.77 & 0.94 & 0.40 & avg. \\
\hline & 0.87 & 2.92 & 1.01 & 0.40 & best \\
\hline \multirow[t]{2}{*}{15} & 0.80 & 2.51 & 0.86 & 0.43 & avg. \\
\hline & 0.82 & 2.57 & 0.90 & 0.43 & best \\
\hline
\end{tabular}

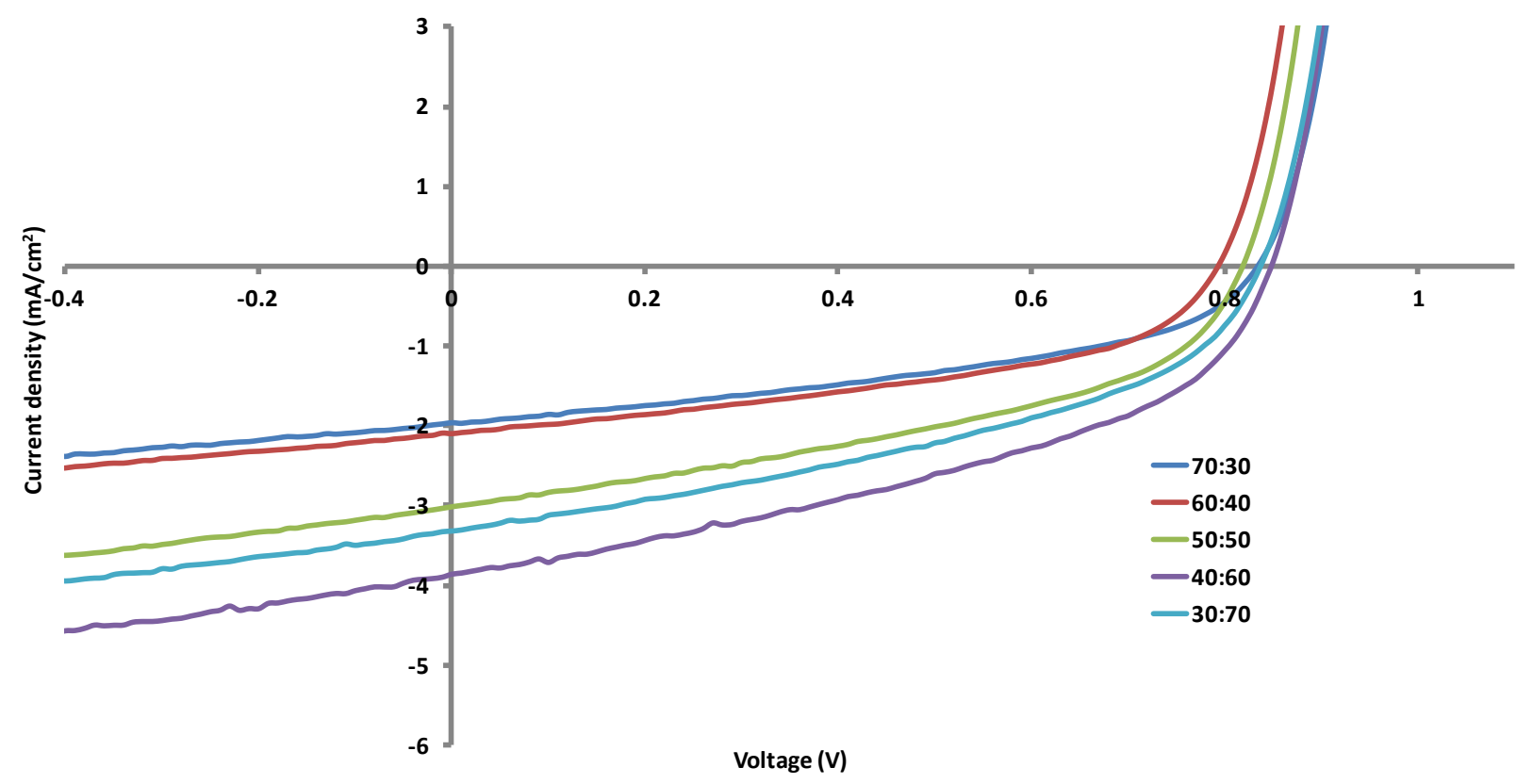

Figure S18: Current density-voltage (JV) curves of PTB7:(7) using $8 \%$ v/v DIO and varying the blend ratio. Note that the 50:50 blend ratio device shows lower performance than the device shown in Figure S19 made under the same conditions, as discussed in the main body of the paper. When all other parameters are fully optimized it is expected that the 40:60 blend will yield the highest performance. 
Table S3: Photovoltaic performance metrics of PTB7:(7) using 8\% v/v DIO and varying the blend ratio.

\begin{tabular}{lrrrrl} 
blend ratio & \multicolumn{3}{c}{ Jsc } & & \\
\hline 70:30 & Voc $(\mathrm{V})$ & $\left(\mathrm{mA} / \mathrm{cm}^{\wedge} 2\right)$ & PCE (\%) & FF & \\
& 0.83 & 1.92 & 0.67 & 0.42 & avg. \\
$60: 40$ & $\mathbf{0 . 8 4}$ & $\mathbf{1 . 9 8}$ & $\mathbf{0 . 7 0}$ & $\mathbf{0 . 4 2}$ & best \\
& 0.77 & 1.97 & 0.67 & 0.44 & avg. \\
$50: 50$ & $\mathbf{0 . 7 9}$ & $\mathbf{2 . 1 0}$ & $\mathbf{0 . 7 4}$ & $\mathbf{0 . 4 4}$ & best \\
& 0.82 & 2.89 & 1.01 & 0.42 & avg. \\
$40: 60$ & $\mathbf{0 . 8 2}$ & $\mathbf{3 . 0 1}$ & $\mathbf{1 . 0 5}$ & $\mathbf{0 . 4 3}$ & best \\
& 0.84 & 3.66 & 1.28 & 0.41 & avg. \\
$30: 70$ & $\mathbf{0 . 8 5}$ & $\mathbf{3 . 8 5}$ & $\mathbf{1 . 3 7}$ & $\mathbf{0 . 4 2}$ & best \\
& 0.83 & 3.19 & 1.10 & 0.42 & avg. \\
& $\mathbf{0 . 8 4}$ & $\mathbf{3 . 3 2}$ & $\mathbf{1 . 1 5}$ & $\mathbf{0 . 4 1}$ & best \\
\hline
\end{tabular}

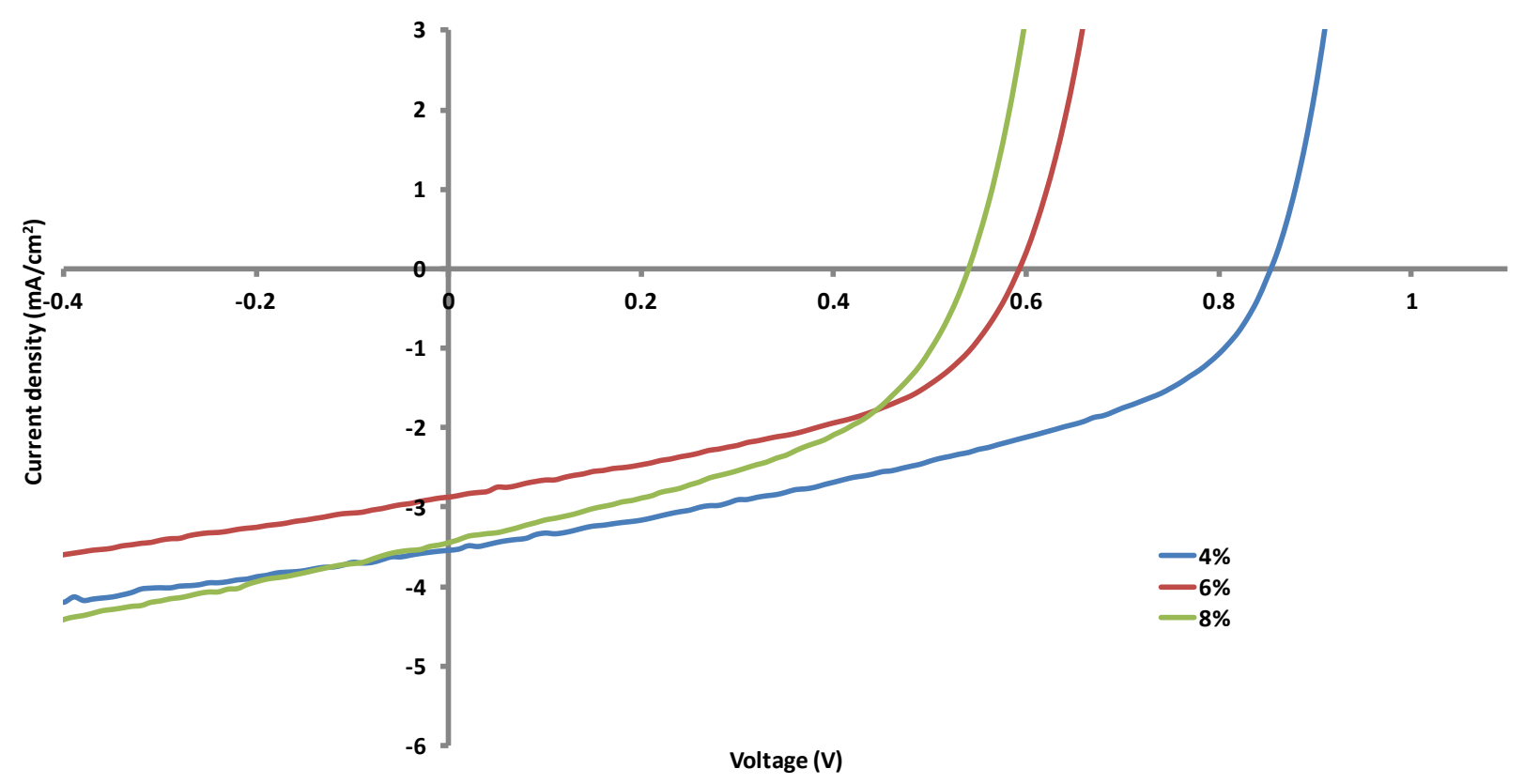

Figure S19: Current density-voltage (JV) curves of PTB7:(7) using a 40:60 ratio and varying the DIO additive. Note that in contrast to Figure S19, higher DIO loading in this batch of devices has a detrimental effect on JV performance, as discussed in the main body of the paper.

Table S4: Photovoltaic performance metrics of PTB7:(7) using a 40:60 ratio and varying the DIO additive.

\begin{tabular}{rrrrrrl} 
DIO additive (\% v/v) & & $\operatorname{Voc}(\mathrm{V})$ & $\begin{array}{r}\text { JSC } \\
\left(\mathrm{mA} / \mathrm{cm}^{\wedge} 2\right)\end{array}$ & PCE (\%) & \multicolumn{1}{c}{ FF } & \\
\hline & 4 & 0.84 & 3.35 & 1.19 & 0.42 & avg.
\end{tabular}




\begin{tabular}{|c|c|c|c|c|}
\hline 0.85 & 3.55 & 1.28 & 0.42 & best \\
\hline 0.60 & 2.81 & 0.73 & 0.45 & avg. \\
\hline 0.59 & 2.87 & 0.79 & 0.46 & best \\
\hline 0.50 & 3.38 & 0.77 & 0.45 & avg. \\
\hline 0.54 & 3.44 & 0.84 & 0.45 & best \\
\hline
\end{tabular}

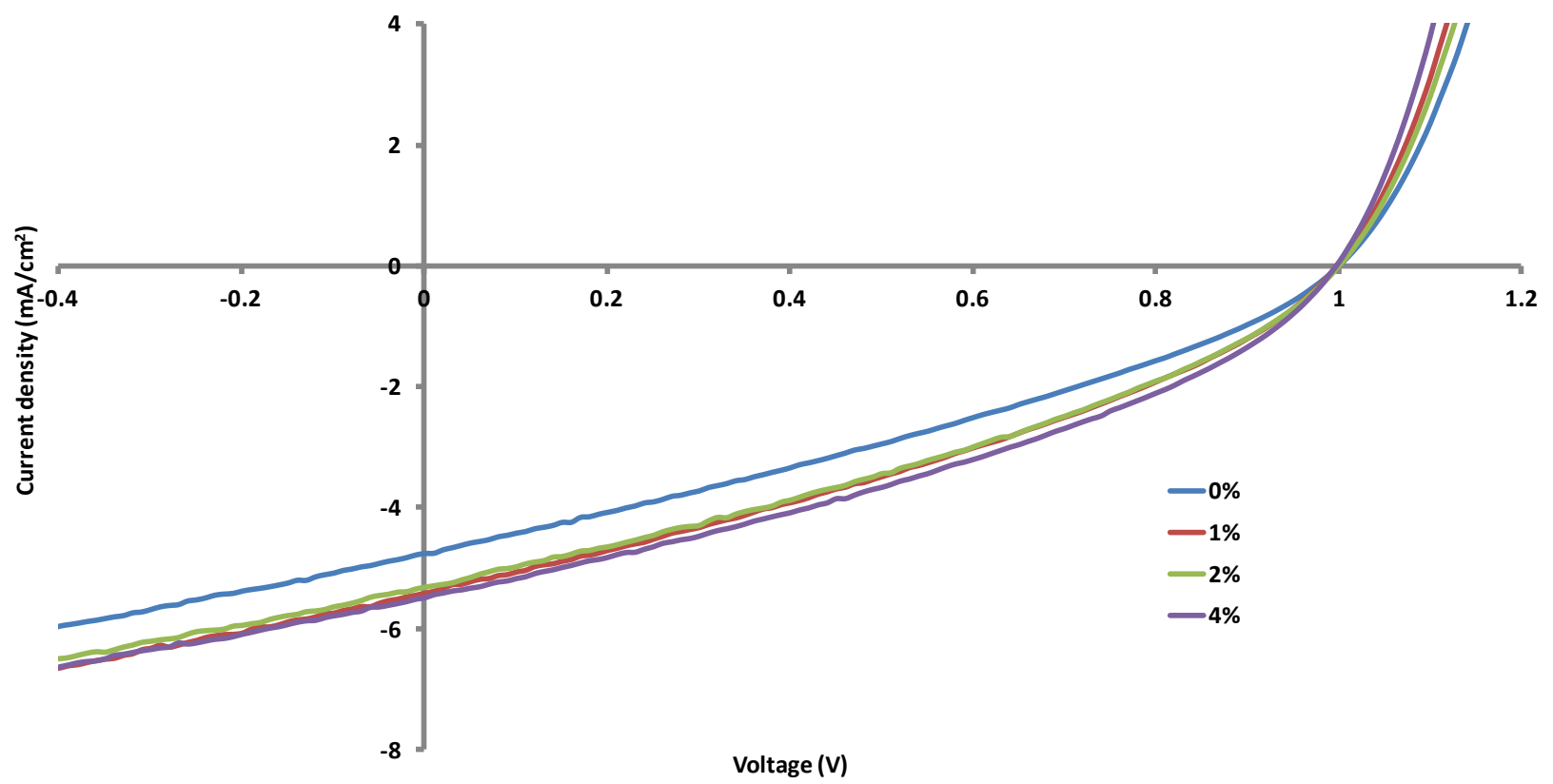

Figure S20: Current density-voltage (JV) curves of PTB7:(5) using a 40:60 blend ratio and varying the DIO additive.

Table S5: Photovoltaic performance metrics of PTB7:(5) using a 40:60 blend ratio and varying the DIO additive.

JSC

\begin{tabular}{lrrrrrl} 
DIO additive (\% v/v) & Voc (V) & $\left(\mathrm{mA} / \mathrm{cm}^{\wedge} 2\right)$ & PCE (\%) & FF & \\
\hline & 0 & 0.95 & 4.45 & 1.30 & 0.29 & avg. \\
& & 1.00 & 4.76 & $\mathbf{1 . 5 1}$ & $\mathbf{0 . 3 2}$ & best \\
& 1 & 1.00 & 4.94 & 1.66 & 0.33 & avg. \\
& & 1.00 & $\mathbf{5 . 4 1}$ & $\mathbf{1 . 8 1}$ & $\mathbf{0 . 3 4}$ & best \\
& 2 & 0.99 & 4.97 & 1.67 & 0.34 & avg. \\
& 1.00 & $\mathbf{5 . 3 2}$ & $\mathbf{1 . 8 1}$ & $\mathbf{0 . 3 4}$ & best \\
& 4 & 1.00 & 5.18 & 1.81 & 0.35 & avg. \\
& 1.00 & $\mathbf{5 . 4 9}$ & $\mathbf{1 . 9 3}$ & $\mathbf{0 . 3 5}$ & best \\
\hline
\end{tabular}




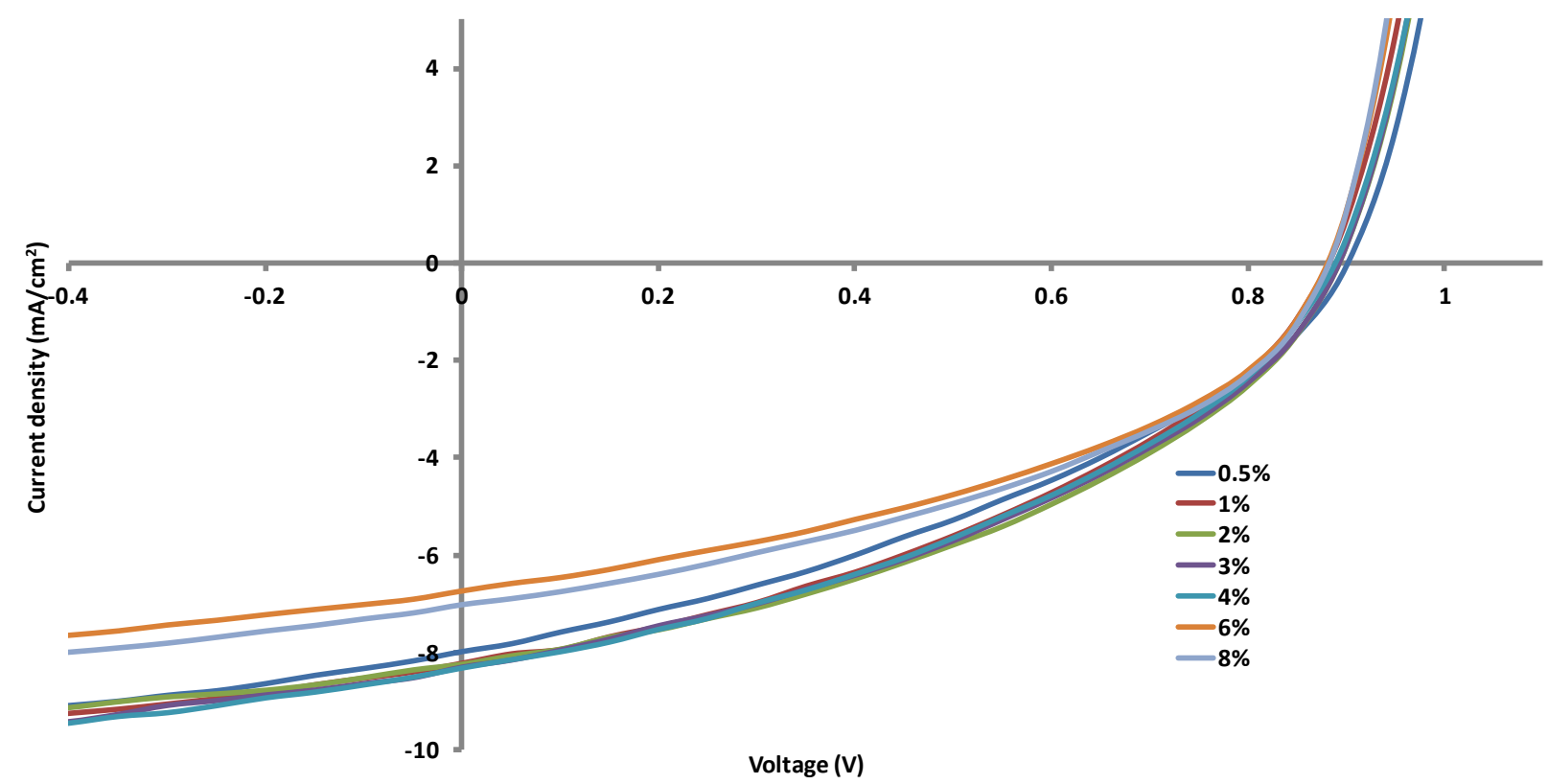

Figure S21: Current density-voltage (JV) curves of PTB7:(7b) using a 40:60 blend ratio and varying the DIO additive.

Table S6: Photovoltaic performance metrics of PTB7:(5) using a 40:60 blend ratio and varying the DIO additive.

\begin{tabular}{|c|c|c|c|c|c|}
\hline DIO additive (\% v/v) & $\operatorname{Voc}(\mathrm{V})$ & $\begin{array}{r}\mathrm{Jsc} \\
\left(\mathrm{mA} / \mathrm{cm}^{\wedge} 2\right)\end{array}$ & PCE (\%) & $\mathrm{FF}$ & \\
\hline 0.5 & 0.91 & 7.67 & 2.63 & 0.38 & avg. \\
\hline & 0.91 & 8.05 & 2.77 & 0.38 & best \\
\hline 1 & 0.88 & 7.98 & 2.67 & 0.38 & avg. \\
\hline & 0.89 & 8.16 & 2.79 & 0.38 & best \\
\hline 2 & 0.89 & 7.85 & 2.84 & 0.40 & avg. \\
\hline & 0.89 & 8.19 & 3.00 & 0.41 & best \\
\hline 3 & 0.91 & 8.03 & 2.86 & 0.39 & avg. \\
\hline & 0.91 & 8.34 & 3.00 & 0.40 & best \\
\hline 4 & 0.90 & 8.05 & 2.89 & 0.40 & avg. \\
\hline & 0.90 & 8.31 & 2.98 & 0.40 & best \\
\hline 6 & 0.90 & 6.45 & 2.43 & 0.42 & avg. \\
\hline & 0.89 & 6.79 & 2.55 & 0.42 & best \\
\hline 8 & 0.90 & 6.79 & 2.54 & 0.42 & avg. \\
\hline & 0.90 & 7.12 & 2.68 & 0.42 & best \\
\hline
\end{tabular}




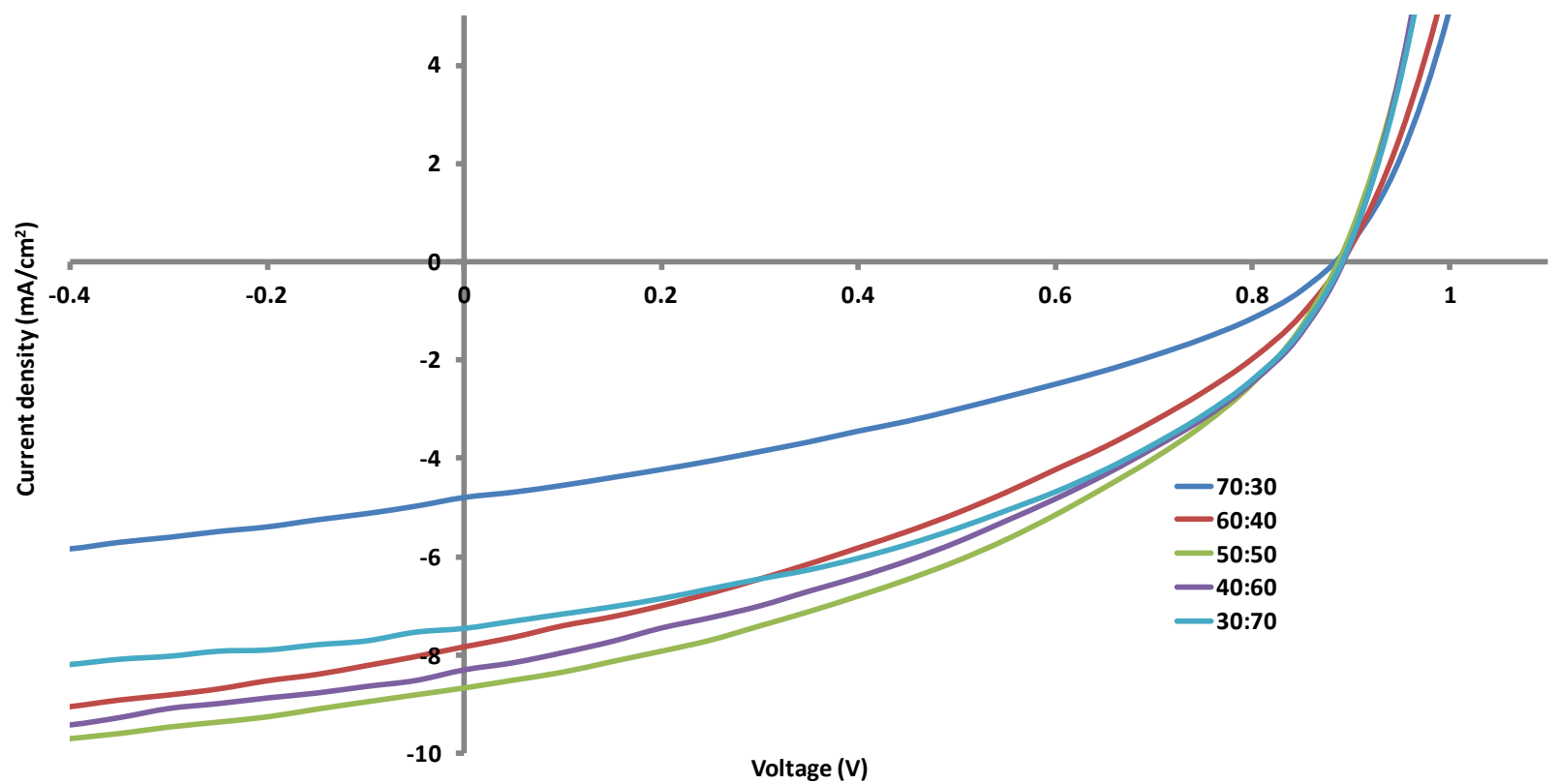

Figure S22: Current density-voltage (JV) curves of PTB7:(7b) using 3\% v/v DIO and varying the blend ratio.

Table S7: Photovoltaic performance metrics of PTB7:(5) using 3\% v/v DIO and varying the blend ratio.

\begin{tabular}{|c|c|c|c|c|c|}
\hline \multirow[b]{2}{*}{ blend ratio } & \multicolumn{4}{|c|}{ Jsc } & \\
\hline & Voc (V) & $\left(\mathrm{mA} / \mathrm{cm}^{\wedge} 2\right)$ & PCE (\%) & $\mathrm{FF}$ & \\
\hline \multirow[t]{2}{*}{ 70:30 } & 0.89 & 4.65 & 1.47 & 0.36 & avg. \\
\hline & 0.89 & 4.84 & 1.55 & 0.36 & best \\
\hline \multirow[t]{2}{*}{$60: 40$} & 0.90 & 7.54 & 2.51 & 0.37 & avg. \\
\hline & 0.91 & 7.82 & 2.63 & 0.37 & best \\
\hline \multirow[t]{2}{*}{$50: 50$} & 0.90 & 8.24 & 3.00 & 0.40 & avg. \\
\hline & 0.91 & 8.55 & 3.13 & 0.40 & best \\
\hline \multirow[t]{2}{*}{$40: 60$} & 0.91 & 8.03 & 2.86 & 0.39 & avg. \\
\hline & 0.91 & 8.34 & 3.00 & 0.40 & best \\
\hline \multirow[t]{2}{*}{$30: 70$} & 0.91 & 7.30 & 2.95 & 0.44 & avg. \\
\hline & 0.93 & 7.47 & 3.07 & 0.44 & best \\
\hline
\end{tabular}




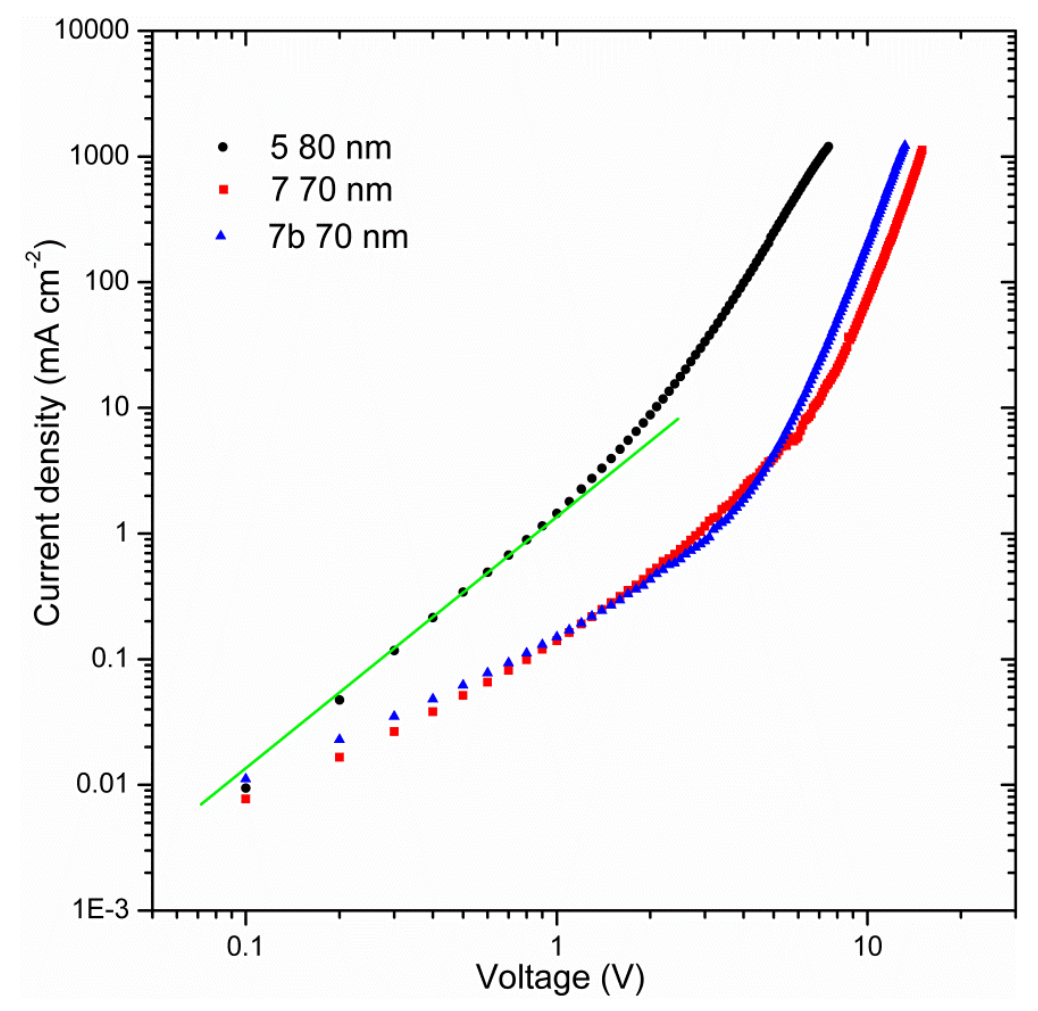

Figure S23. JV curves of electron devices of compounds 5,7 , and $7 \mathrm{~b}$. The straight line superimposed on data points for compound 5 corresponds to a slope of $2\left(V^{2}\right.$ dependence).

Figure S23 above shows the JV characteristics of electron only devices (ITO/ZnO/PDI/Ca/Ag). In the absence of charge-injection barriers or trapping states in the semiconductor film, space charge limited current density (SCLC) through the device follows the Mott-Gurney equation (Child's law for solids):

$$
J=\frac{9}{8} \mu \varepsilon_{0} \varepsilon_{r} \frac{V^{2}}{L^{3}}
$$

where $\mu$ is the charge-carrier mobility, $\varepsilon_{0}$ is the free-space permittivity, $\varepsilon_{r}$ is the dielectric constant of the semiconductor, $\mathrm{V}$ is the bias across the device, and $\mathrm{L}$ is the semiconductor film thickness. Organic semiconductor films are rarely trap free, so the SCLC model is typically inapplicable. However, in compound 5 under the low bias regime $(0.1-1 \mathrm{~V})$, current densities corresponding to a $\mathrm{V}^{2}$ dependence is observed. At higher biases, the power-law scaling of the current density with voltage is larger than 2 , indicating trap-limited current. Since the current densities and average electric field in this regime are comparable to OPV operating conditions, the carrier densities are also expected to be comparable to OPV operating conditions. Electron mobilities for compound 5 for two film thicknesses ( 80 and $115 \mathrm{~nm}$ ) derived from the Mott-Gurney equation both correspond to $2 \times 10^{-6} \mathrm{~cm}^{2} \mathrm{~V}^{-1} \mathrm{~s}^{-1}$. Since this mobility is attained in the presence of traps, this places a lower limit on the SCLC (trap free) mobility. For compounds 7 and $7 \mathrm{~b}$, the current densities under the same bias are approximately an order of magnitude lower than for compound 5. This places a lower limit on the SCLC mobility of 7 and $7 \mathrm{~b}$ to be $10^{-7} \mathrm{~cm}^{2} \mathrm{~V}^{-1} \mathrm{~s}^{-1}$. 


\section{Atomic Force Microscopy (AFM)}

AFM images were taken using a Bruker Innova atomic force microscope in tapping mode using Bruker TESPA probes. Images were post-processed using the Bruker NanoScope analysis software flattening routines
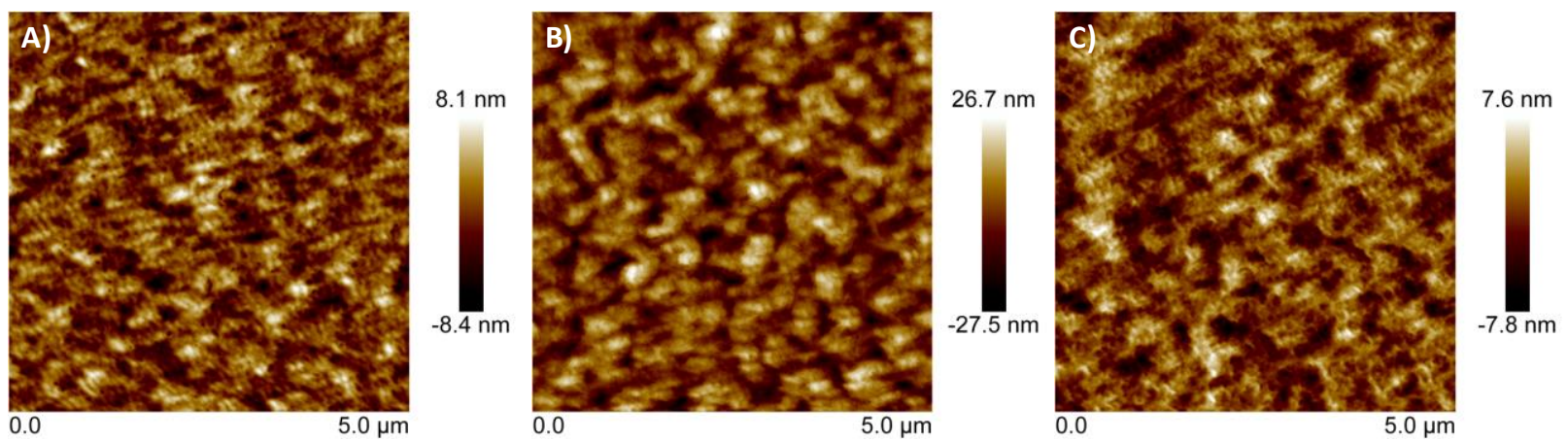

Figure S24: AFM topography images of optimized BHJ blend films using PTB7 donor polymer processed from CB with DIO additive: A) PTB7:(5) (PCE $=1.93 \%)$, B) PTB7:(7) (PCE $=2.21 \%)$, C) PTB7:(7b) (PCE $=$ $3.13 \%)$.
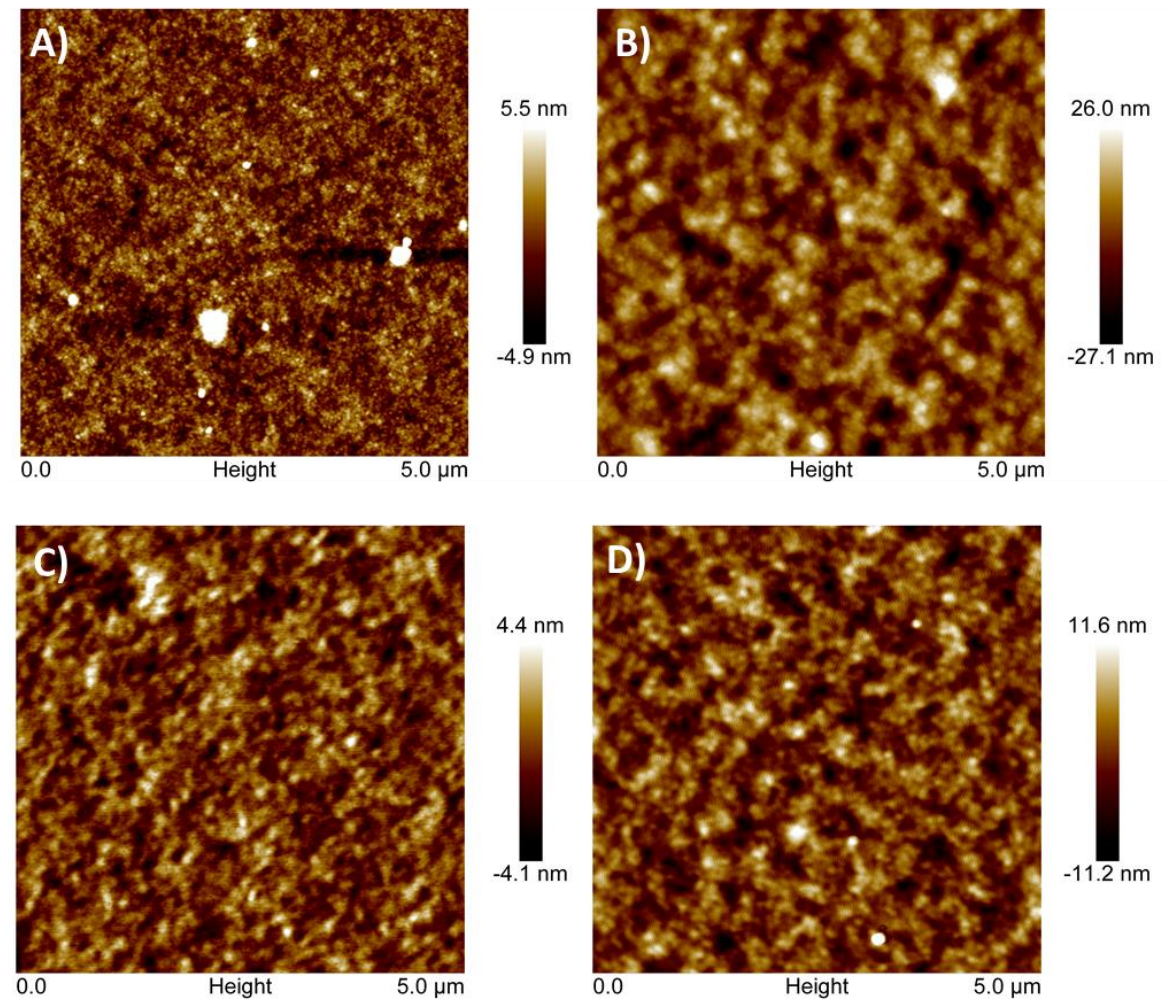

Figure S25: AFM topography images of BHJ blend films using PTB7-Th donor polymer processed from CB with and without DIO additive: A) PTB7-Th:(7) (PCE = 5.13\%), B) PTB7-Th:(7) + 8\% DIO (PCE = 5.04\%), C) PTB7-Th:(7b) (PCE = 5.54\%), D) PTB7-Th:(7b) + 3\% DIO (PCE = 5.43\%). 


\section{Details on Device Fabrication of Organic Solar Cells using P3TEA (Yan)}

Pre-patterned ITO-coated glass with sheet resistance of $15 \Omega$ per square centimeter was used as the substrate. The glass substrate was cleaned by the sequential sonication in soap DI water, DI water, acetone and isopropanol for $30 \mathrm{~min}$ each step. After that, the glass substrate was treated by ultraviolet/ozone cleaner (Novascan, PSD Series digital UV ozone system) for $30 \mathrm{~min}$. A ZnO (The diethylzinc solution $15 \mathrm{wt} \%$ in toluene, diluted with tetrahydrofuran) electron transport layer was cast on the substrate by spin coating at spin rate of 5000 r.p.m. for $30 \mathrm{~s}$ and then baked in air at $180^{\circ} \mathrm{C}$ for 30 min in a dry box (relative humidity below 5\%). Active layer solutions (P3TEA:7b weight ratio 1:1.5) were prepared in TMB and using 2.5\% ODT as additive. The polymer concentration was $8 \mathrm{mg} / \mathrm{ml}$. To completely dissolve the polymer, the active layer solution was stirred on a hot plate at $100^{\circ} \mathrm{C}$ for 2 hours. Before spin coating, both the polymer solution and ITO substrate were preheated on a hot plate at $\sim 95^{\circ} \mathrm{C}$. Active layers were spin coated from the warm polymer solution onto the preheated substrate in a $\mathrm{N}_{2}$ glovebox at $\sim 1400$ r.p.m. The active layer then treated with vacuum to remove the high boiling point additives. The blend films were annealed at $100^{\circ} \mathrm{C}$ for $5 \mathrm{~min}$. After that, the cast films were transferred to a thermal evaporator inside the same glovebox. At a vacuum level of $3 \times 10^{-6} \mathrm{Torr}$, a thin layer $(2 \mathrm{~nm})$ of $\mathrm{V}_{2} \mathrm{O}_{5}$ was deposited as the anode interlayer, followed by deposition of $100 \mathrm{~nm}$ of $\mathrm{Al}$ as the top electrode. All cells were encapsulated using epoxy inside the glovebox. Device J-V characteristics was measured under air mass 1.5 global $\left(100 \mathrm{mWcm}^{-2}\right)$ using a Newport Class a solar simulator (94021A, a Xenon lamp with an AM1.5G filter). A standard crystalline Si solar cell with a KG5 filter was purchased from PV measurements and calibrated by Newport Corporation. The light intensity was calibrated using the standard Si diode to bring spectral mismatch to unity. J-V characteristics were recorded using Keithley 236 or 2400 source meter unit. Typical cells have devices area of $\sim 5.9 \mathrm{~mm} 2$, which is defined by a metal mask with an aperture aligned with the device area.

\section{Optical and Electronic Characterization}

Table S9. Summary of Optical and Electronic Characterization data for (2), (4), (5) and (7)

\begin{tabular}{c|c|c|c|c|c|c|c}
\hline Compound & $\begin{array}{c}\lambda_{\max }(\mathrm{nm}) \\
\text { sol'n }\end{array}$ & $\begin{array}{c}\lambda_{\text {on }}(\mathrm{nm}) \\
\text { soln }\end{array}$ & $\begin{array}{c}\lambda_{\max }(\mathrm{nm}) \\
\text { film }\end{array}$ & $\begin{array}{c}\lambda_{\text {on }}(\mathrm{nm}) \\
\text { film }\end{array}$ & $\mathrm{IP}(\mathrm{eV})$ & $\mathrm{EA}(\mathrm{eV})$ & $\mathrm{Eg}(\mathrm{eV})$ \\
\hline $\mathbf{( 2 )}$ & 525 & 550 & 495 & 624 & 5.9 & 3.6 & 2.3 \\
(4) & 521 & 551 & 533 & 611 & 5.8 & 3.6 & 2.2 \\
(5) & 530 & 558 & 496 & 614 & 5.7 & 3.5 & 2.2 \\
(7) & 533 & 550 & 533 & 624 & 6.0 & 3.8 & 2.2
\end{tabular}




\section{Crystal Structure Data}

Table S8. Crystal Data Collection and Refinement Parameters for 5 and 7.

\begin{tabular}{|c|c|c|}
\hline & 5 & 7 \\
\hline chemical formula & $\mathrm{C}_{40} \mathrm{H}_{39} \mathrm{~N}_{3} \mathrm{O}_{4}, \mathrm{C}_{7} \mathrm{H}_{8}$ & $6\left(\mathrm{C}_{80} \mathrm{H}_{79} \mathrm{~N}_{6} \mathrm{O}_{8}\right), \mathrm{C}_{7} \mathrm{H}_{8}$ \\
\hline crystal colour & Red & Red \\
\hline$F w ; F(000)$ & $717.87 ; 1528$ & $7609.51 ; 8085$ \\
\hline$T(\mathrm{~K})$ & $100(2)$ & $100(2)$ \\
\hline wavelength (Å) & 0.68881 & 0.97949 \\
\hline space group & $\mathrm{Cc}$ & P-1 \\
\hline$a(\AA)$ & $13.794(3)$ & $24.169(5)$ \\
\hline$b(\AA)$ & $37.421(8)$ & $28.466(6)$ \\
\hline$c(\AA)$ & $7.3040(15)$ & $32.063(6)$ \\
\hline$\alpha$ (deg) & 90 & $99.55(3)$ \\
\hline$\beta$ (deg) & $98.43(3)$ & $96.51(3)$ \\
\hline Y (deg) & 90 & $94.85(3)$ \\
\hline$Z$ & 4 & 2 \\
\hline$V\left(\AA^{3}\right)$ & $3729.5(13)$ & $21493(8)$ \\
\hline$\rho_{\text {calcd }}\left(\mathrm{g} \cdot \mathrm{cm}^{-3}\right)$ & 1.279 & 1.176 \\
\hline$\mu\left(\mathrm{mm}^{-1}\right)$ & 0.075 & 0.161 \\
\hline$\theta$ range (deg); completeness & $1.055-24.992 ; 1.000$ & $0.895-22.131 ; 0.986$ \\
\hline collected reflections; $R_{\sigma}$ & $26765 ; 0.0272$ & $59864 ; 0.1159$ \\
\hline unique reflections; $R_{\text {int }}$ & $26765 ; 0.0323$ & $59864 ; 0.0901$ \\
\hline $\mathrm{R1}^{\mathrm{a}} ; \mathbf{w R 2}^{\mathrm{b}}[\mathrm{I}>2 \sigma(\mathrm{I})]$ & $0.0578 ; 0.1569$ & $0.2172 ; 0.5215$ \\
\hline R1; wR2 [all data] & $0.0627 ; 0.1615$ & $0.2384 ; 0.5474$ \\
\hline GOF & 1.041 & 2.571 \\
\hline largest diff peak and hole & 0.441 and -0.378 & 0.700 and -0.534 \\
\hline
\end{tabular}


A)

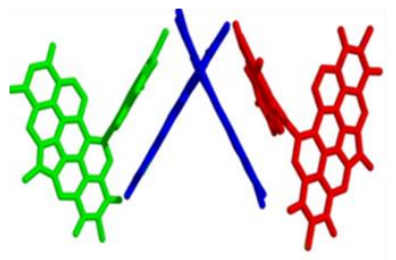

B)

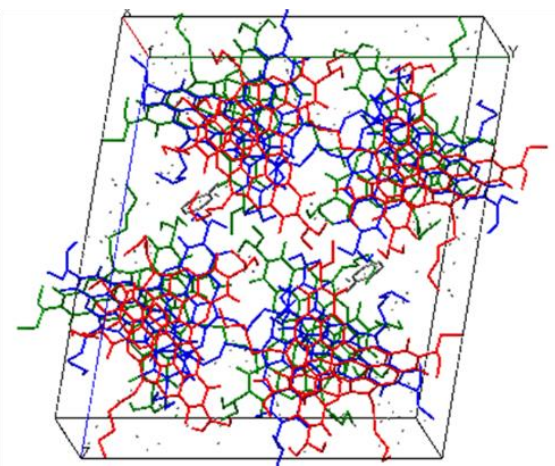

C)

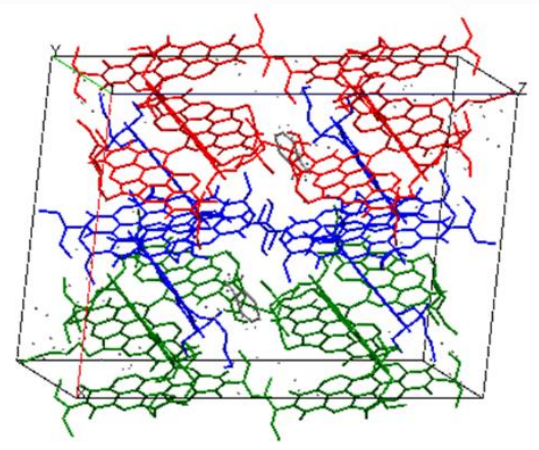

Figure S26: A) A trimer of $\pi$-stacked molecules of compound 7. B) Shown along the a* axis of the unit cell, four $\pi$-stacks of $\mathbf{7}$ are located per unit-cell, separated in the interstitial regions by the compound's alkyl chains. C) Shown along the $b^{*}$ axis of the unit cell.

\section{Thermal Analysis}

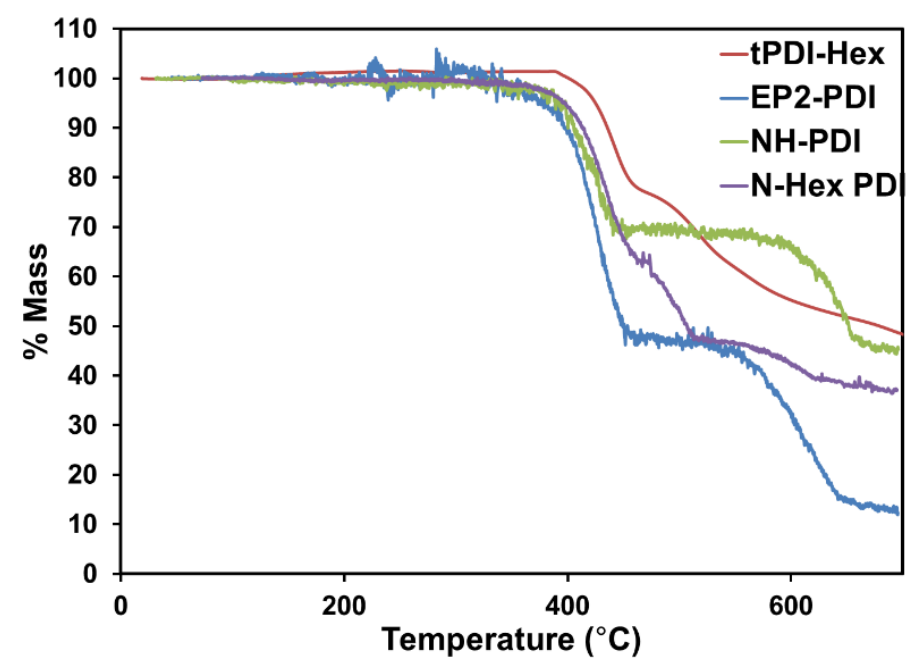

Figure S27: Thermal gravimetric analysis of 2, 4, 5, and 7. Decomposition was determined at $5 \%$ mass loss. $\mathbf{2}=\sim 395^{\circ} \mathrm{C}, \mathbf{4}=\sim 395^{\circ} \mathrm{C}, \mathbf{5}=\sim 395^{\circ} \mathrm{C}, \mathbf{7}=\sim 395^{\circ} \mathrm{C}$. 


\section{References}

(1) Frisch, M.; Trucks, G.; Schlegel, H.; Scuseria, G.; Robb, M.; Cheeseman, J.; Scalmani, G.; Barone, V.; Mennucci, B.; Petersson, G.; Nakatsuji, H.; Caricato, M.; Li, X.; Hratchian, H.; Izmaylov, A.; Bloino, J.; Zheng, G.; Sonnenberg, J.; Hada, M.; Ehara, M.; Toyota, K.; Fukuda, R.; Hasegawa, J.; Ishida, M.; Nakajima, T.; Honda, Y.; Kitao, O.; Nakai, H.; Vreven, T.; Montgomery, J.; Peralta, J.; Ogliaro, F.; Bearpark, M.; Heyd, J.; Brothers, E.; Kudin, K.; Staroverov, V.; Kobayashi, R.; Normand, J.; Raghavachari, K.; Rendell, A.; Burant, J.; Iyengar, S.; Tomasi, J.; Cossi, M.; Rega, N.; Millam, J.; Klene, M.; Knox, J.; Cross, J.; Bakken, V.; Adamo, C.; Jaramillo, J.; Gomperts, R.; Stratmann, R.; Yazyev, O.; Austin, A.; Cammi, R.; Pomelli, C.; Ochterski, J.; Martin, R.; Morokuma, K.; Zakrzewski, V.; Voth, G.; Salvador, P.; Dannenberg, J.; Dapprich, S.; Daniels, A.; Farkas; Foresman, J.; Ortiz, J.; Cioslowski, J.; Fox, D. Gaussian 09 Revis. B01 Gaussian Inc Wallingford CT 2009.

(2) GaussView Version 5.

(3) Becke, A. D. Phys. Rev. A 1988, 38 (6), 3098.

(4) Lee, C.; Yang, W.; Parr, R. G. Phys. Rev. B 1988, 37 (2), 785.

(5) Miehlich, B.; Savin, A.; Stoll, H.; Preuss, H. Chem. Phys. Lett. 1989, 157 (3), 200.

(6) Hehre, W. J.; Ditchfield, R.; Pople, J. A. J. Chem. Phys. 1972, 56 (5), 2257.

(7) Hariharan, P. C.; Pople, J. A. Theor. Chim. Acta 1973, 28 (3), 213.

(8) Francl, M. M.; Pietro, W. J.; Hehre, W. J.; Binkley, J. S.; Gordon, M. S.; DeFrees, D. J.; Pople, J. A. J. Chem. Phys. 1982, 77 (7), 3654.

(9) Binning, R. C.; Curtiss, L. A. J. Comput. Chem. 1990, 11 (10), 1206.

(10) Rassolov, V. A.; Pople, J. A.; Ratner, M. A.; Windus, T. L. J. Chem. Phys. 1998, 109 (4), 1223.

(11) Rassolov, V. A.; Ratner, M. A.; Pople, J. A.; Redfern, P. C.; Curtiss, L. A. J. Comput. Chem. 2001, 22 (9), 976.

(12) Bauernschmitt, R.; Ahlrichs, R. Chem. Phys. Lett. 1996, 256 (4-5), 454.

(13) Grochulski, P.; Fodje, M. N.; Gorin, J.; Labiuk, S. L.; Berg, R. J. Synchrotron Radiat. 2011, 18 (4), 681.

(14) Kabsch, W. J. Appl. Crystallogr. 1993, 26 (6), 795.

(15) Sheldrick, G. M. Sadabs; University of Göttingen, Germany Program for Empirical Absorption Correction of Area Detector Data, 1996.

(16) Sheldrick, G. M. XDS2SAD.; University of Gottingen, Germany, 2008.

(17) XPREP 2014; X-ray data Preparation and Reciprocal space Exploration Program.; Bruker AXS Inc.,: Madison, Wisconsin, USA., 2014.

(18) Sheldrick, G. M. Acta Crystallogr. Sect. C Struct. Chem. 2015, 71 (1), 3.

(19) Emsley, P.; Lohkamp, B.; Scott, W. G.; Cowtan, K. Acta Crystallogr. Sect. D 2010, 66 (4), 486.

(20) Spek, A. L. Acta Crystallogr. Sect. D 2009, 65 (2), 148.

(21) LinXTL is a local program and it could be obtained free of charge from http://sourceforge.net/projects/linxtl/.

(22) Macrae, C. F.; Bruno, I. J.; Chisholm, J. A.; Edgington, P. R.; McCabe, P.; Pidcock, E.; RodriguezMonge, L.; Taylor, R.; van de Streek, J.; Wood, P. A. J. Appl. Crystallogr. 2008, 41 (2), 466.

(23) The PyMOL Molecular Graphics System, Version 1.8 Schrödinger, LLC.

(24) Demmig, S.; Langhals, H. Chem. Ber. 1988, 121 (2), 225.

(25) Chen, K.-Y.; Chow, T. J. Tetrahedron Lett. 2010, 51 (45), 5959.

(26) Freeman, A. W.; Urvoy, M.; Criswell, M. E. J. Org. Chem. 2005, 70 (13), 5014.

(27) Qiu, S.; Liu, L.; Wang, B.; Shen, F.; Zhang, W.; Li, M.; Ma, Y. Macromolecules 2005, 38 (16), 6782.

(28) Meng, D.; Sun, D.; Zhong, C.; Liu, T.; Fan, B.; Huo, L.; Li, Y.; Jiang, W.; Choi, H.; Kim, T.; Kim, J. Y.; Sun, Y.; Wang, Z.; Heeger, A. J. J. Am. Chem. Soc. 2016, 138 (1), 375. 